\title{
Olfactory Horizontal Basal Cells Demonstrate a Conserved Multipotent Progenitor Phenotype
}

\author{
Lindsay A. Carter, Jessica L. MacDonald, and A. Jane Roskams \\ Department of Zoology and Center for Molecular Medicine and Therapeutics, University of British Columbia, V6T 1Z4 Vancouver, Canada
}

\begin{abstract}
Stem cells of adult regenerative organs share a common goal but few established conserved mechanisms. Within the neural stem cell niche of the mouse olfactory epithelium, we identified a combination of extracellular matrix (ECM) receptors that regulate adhesion and mitosis in non-neural stem cells [intercellular adhesion molecule-1 (ICAM-1), $\beta_{1}, \beta_{4}$, and $\alpha-1,-3$, and -6 integrins] and on horizontal basal cells (HBCs), candidate olfactory neuro-epithelial progenitors. Using ECM receptors as our guide, we recreated a defined microenvironment in vitro that mimics olfactory basal lamina and, when supplemented with epidermal growth factor, transforming growth factor $\alpha$, and leukemia inhibitory factor, allows us to preferentially expand multiple clonal adherent colony phenotypes from individual ICAM- $1+$ and ICAM- $1+/ \beta_{1}$ integrin +-selected HBCs. The most highly mitotic colony-forming HBCs demonstrate multipotency, spontaneously generating more ICAM-positive presumptive HBCs, a combination of olfactory neuroglial progenitors, and neurons of olfactory and potentially nonolfactory phenotypes. HBCs thus possess a conserved adhesion receptor expression profile similar to non-neural stem cells, preferential self-replication in an in vitro environment mimicking their in vivo niche, and contain subpopulations of cells that can produce multiple differentiated neuronal and glial progeny from within and beyond the olfactory system in vitro.
\end{abstract}

Key words: degeneration; development; olfactory; progenitor; extracellular matrix; gliogenesis

\section{Introduction}

The mammalian olfactory system has historically been considered a hotspot for endogenous adult neurogenesis (Schwob, 2002). More recently, the migration and differentiation of olfactory bulb-bound subventricular zone (SVZ)-derived rostral migratory stream (RMS) progenitors has taken center stage (Luskin, 1993; van der Kooy and Weiss, 2000), but it is at the peripheral end of the olfactory neuraxis, in the olfactory neuroepithelium $(\mathrm{OE})$, where prolific functional neurogenesis has been established for more than 30 years (Graziadei and Graziadei, 1979b; Farbman, 1990). In the OE, apoptotic olfactory receptor neurons (ORNs) are replaced by new neurons derived from basally situated progenitor populations to help maintain the sense of olfaction during the lifetime of an organism (Carr and Farbman, 1992; Huard et al., 1998).

The OE is thus an accessible source of peripheral adult neuroglial progenitors ("potential stem cells"), but a means of identifying candidate quiescent $\mathrm{OE}$ stem cell and progenitor popula-

\footnotetext{
Received Jan. 29, 2004; revised April 18, 2004; accepted May 6, 2004.

This work was supported by a Rick Hansen Neurotrauma studentship to L.A.C., a Paetzold fellowship to J.L.M., and a Canadian Institutes of Health (199907TOP-76703)/Canadian Neurotrauma Partnership program grant to A.J.R. We thank Andrea Griffiths for technical assistance and members of the Roskams Laboratory for discussion of this manuscript. We thank Linda Barlow (University of Colorado Health Sciences Center, Denver, C0), Dr. Frank Margolis (University of Maryland, Baltimore, MD), and Barbara Murdoch for critical reading of this manuscript; Barbara Murdoch and Andy Johnson for assistance with fluorescence-activated cell sorting analysis; and Dr. Frank Margolis and Dr. Jim Schwob (Tufts University, Boston, MA) for their generous gifts of olfactory marker protein and globose basal cells 1, 2, and 3 antibodies. We also thank Edward Au for artistic contributions to Figure 9.

Correspondence should be addressed to Dr. Jane Roskams, University of British Columbia, Department of Zoology, 6270 University Boulevard, Room 3479, Vancouver, British Columbia V6T 124, Canada. E-mail: roskams@zoology.ubc.ca.

D0I:10.1523/JNEUROSCI.0330-04.2004

Copyright $\odot 2004$ Society for Neuroscience $\quad 0270-6474 / 04 / 245670-14 \$ 15.00 / 0$
}

tions has thus far remained elusive. This is because of a common problem in progenitor biology, a lack of readily identifiable markers to select undifferentiated quiescent neural stem cells (NSCs) from an adult tissue before they divide and assume a more differentiated phenotype (Weiss and van der Kooy, 1998; Gage, 2000). Thus, there is an essential need for understanding the pathways that combine to regulate neural stem cells in vivo, to guide how to manipulate them in vitro, or regulate their activation from quiescence in the context of repair strategies (McKay, 2000). ORN progenitors have been localized to the basal cell compartment of the OE, and globose basal cells (GBCs) in particular have been identified as neuronal precursors for ORNs (Graziadei and Graziadei, 1979b; Calof and Chikaraishi, 1989; Caggiano et al., 1994; Schwob et al., 1994; Huard et al., 1998). GBCs are neurogenic, their differentiation is regulated by bone morphogenetic protein 4 and FGF2, and they appear to have a limited ability to self-replicate (Calof and Chikaraishi, 1989; DeHamer et al., 1994; Shou et al., 1999). In contrast, their neighbors, horizontal basal cells (HBCs), are a relatively quiescent population, that both in vivo and in explant or mixed culture are epidermal growth factor (EGF) and transforming growth factor $\alpha$ (TGF $\alpha$ ) responsive (Mahanthappa and Schwarting, 1993; Farbman and Buchholz, 1996; Getchell et al., 2000). Although GBCs clearly contain neuronal progenitors, other basally situated stable multipotent neuroglial progenitors and glial progenitors likely exist in the OE.

The OE is arranged in a hierarchical manner, much like the epithelia of the colon and epidermis, where progenitors, transit amplifying cells, and mature terminally differentiated cells occupy discrete laminas, each capable of both lateral and hierarchical control of the adjacent population (Booth and Potten, 2000; 
Watt, 2002). In these non-neuronal systems, the stem cell niche is defined primarily by adhesion to a defined basal lamina or stroma, where adhesion mechanisms regulate stem cell proliferation and inhibit differentiation (Zhu et al., 1999; Watt, 2002). We thus decided to test the hypothesis that these same integrindriven mechanisms might also regulate progenitors within the nervous system environment of the OE. By following the mechanistic lead of stem cells beyond the nervous system, we hypothesize that common cellular and extracellular substrates might also define the in vivo niche of OE progenitors and, once identified, may allow us to isolate and control the behavior of individual selected progenitors in vitro to assay their potential as stem cells for the OE.

\section{Materials and Methods}

\section{Olfactory bulbectomies and tissue preparation}

Unilateral bulbectomies on adult outbred CD-1 mouse strain (CD-1 mice) (6 weeks of age) were performed as described previously (Roskams et al., 1996). The presence of complete lesion was verified both visually and microscopically. After recovery from anesthesia, animals were maintained according to University of British Columbia Animal Care and Use protocols until they were killed at 2-14 d postbulbectomy. Mice were perfused with PBS and 4\% paraformaldehyde as described previously (Cowan et al., 2001). The brain and olfactory epithelium were dissected, immersion fixed in $4 \%$ paraformaldehyde for $2 \mathrm{hr}$, and then sequentially bathed in 10 and $30 \%$ sucrose to cryoprotect. Tissue was embedded in plastic molds with OCT compound (Tissue-Tek; Baxter, Columbia, MD) over liquid nitrogen. Cryostat sections $(10-14 \mu \mathrm{m})$ were then cut and frozen until needed.

\section{Bromodeoxyuridine incorporation and detection}

Mice were injected with $30 \mathrm{mg} / \mathrm{kg}$ bromodeoxyuridine (BrdU) (Sigma, St. Louis, MO) at 3 and $1 \mathrm{hr}$ before they were killed. Tissue sections were processed according to standard immunohistochemistry protocols (see below) with the exception that a 20 min treatment in $4 \mathrm{M} \mathrm{HCl}$ was required before the incubation with primary antibody. BrdU incorporation was visualized using monoclonal mouse anti-BrdU alkaline phosphatase (Roche Diagnostics, Mannheim, Germany) or monoclonal unconjugated mouse anti-BrdU G3G4 (1:500; Developmental Studies Hybridoma Bank, Iowa City, IA) recognized by a fluorescently labeled secondary antibody.

\section{Immunohistochemistry}

Frozen sections were rehydrated in PBS for $5 \mathrm{~min}$, permeablized in $0.1 \%$ Triton X-100 (Sigma), blocked with 4\% normal serum, and incubated at $4^{\circ} \mathrm{C}$ for $12-20 \mathrm{hr}$ in primary antibody. Tissue sections were washed and incubated with either biotinylated (Vectastain ABC kit; Vector Laboratories, Burlingame, CA) or fluorophore-conjugated secondary antibodies as described previously (Cowan et al., 2001). HRP activity was visualized with VIP, diaminobenzidine (both from Vector Laboratories), or Amplex red (Molecular Probes, Eugene, OR).

\section{Antibodies}

The following primary antibodies were used for immunohistochemistry: monoclonal hamster anti-mouse intercellular adhesion molecule-1 (ICAM-1) (CD54; 1:100; PharMingen, San Diego, CA), rat anti-mouse $\beta_{1}$ integrin subunit (CD29; 1:100; PharMingen), monoclonal rat antimouse $\beta_{4}$ integrin subunit (CD104; 1:100; PharMingen), rat anti-mouse CD34 (1:100; PharMingen), monoclonal mouse anti-rat $\beta$-III neuronspecific tubulin [NST; 1:500; class III $\beta$-tubulin (TuJ1); BabCo, Richmond, CA), polyclonal rabbit anti-bovine glial fibrillary acidic protein (GFAP; 1:5; Incstar, Stillwater, MN), monoclonal mouse anti-bovine S100 $\beta$ (1:1000; Sigma), polyclonal rabbit anti-mouse p75 low-affinity nerve growth factor receptor (1:1000; Chemicon, Temecula, CA), antiproliferating cell nuclear antigen (PCNA; 1:5000; Sigma), polyclonal goat anti-rat olfactory marker protein (OMP; 1:5000; gift from Dr. F. Margolis, University of Maryland, Baltimore, MD), polyclonal rabbit antichicken neural cell adhesion molecule (NCAM; 1:500; Chemicon), monoclonal mouse anti-rat GBC-2 (undiluted hybridoma; gift from Dr.
J. Schwob, Tufts University, Boston, MA), polyclonal goat $\alpha$ integrins 1 (rat origin), 3 (human origin), and 6 (human origin) (1:100; Santa Cruz Biotechnology, Santa Cruz, CA), polyclonal rabbit anti-rat adenylate cyclase III (1:200; Santa Cruz Biotechnology), polyclonal rabbit anti-rat G $\alpha_{\mathrm{S}}$ /olf (1:1000; Santa Cruz Biotechnology), monoclonal mouse antihuman keratin 903 (undiluted; Enzo Life Sciences, Farmingdale, NY), and polyclonal rabbit anti-mouse laminin (1:1000; Sigma). Biotinylated secondary antibodies used for peroxidase immunohistochemistry were horse anti-hamster (PharMingen), goat anti-rat (Vector Laboratories), goat anti-rabbit (Vector Laboratories), rabbit anti-goat (Vector Laboratories), and horse-anti mouse (Vector Laboratories). Secondary antibodies used for immunofluorescence were goat anti-hamster cyanin (Cy)-2 and Cy-3 (Jackson ImmunoResearch, West Grove, PA), donkey antigoat, goat anti-rabbit Alexa 350, goat anti-mouse, goat anti-rat Alexa 488, and Alexa 594 (Molecular Probes).

\section{Primary culture of basal cells}

For each basal cell preparation, the olfactory epithelium was carefully dissected from a litter of postnatal day (P) $5 \mathrm{CD}-1$ mice into $10 \mathrm{ml}$ of DMEM/F12 (1:1; Invitrogen) prewarmed to $37^{\circ} \mathrm{C}$. Care was taken during dissection to ensure that the forceps tips were not pushed beyond the cribiform plate (into olfactory bulb tissue) or past the olfactory epithelium (to avoid removing adjacent optic tissue). OE tissue was minced to $1 \mathrm{~mm}^{3}$ in size and spun at $110 \times g$ for $10 \mathrm{~min}$. The supernatant was aspirated and the pellet resuspended in $10 \mathrm{ml}$ of DMEM/F12. The suspension was triturated with a $\mathrm{P} 1000$ plastic tip pipettor and spun at $43 \times$ $g$ for $5 \mathrm{~min}$, after which the supernatant was aspirated and the pellet was resuspended in $10 \mathrm{ml}$ of fresh DMEM/F12. The tissue suspension was dissociated enzymatically by incubation with Liberase blendzyme I ( 0.45 $\mathrm{mg} / \mathrm{ml}$; Roche), hyaluronidase ( $1 \mathrm{mg} / \mathrm{ml}$; Sigma), and DNase I ( $1 \mathrm{mg} / \mathrm{ml}$; Roche) for $1 \mathrm{hr}$ in a $37^{\circ} \mathrm{C}$ water bath with occasional swirling to resuspend tissue. Initial experiments determined that these digestion conditions produced the best yield of basal cells in culture. After enzymatic dissociation, the suspension was triturated and filtered through a sterile $80 \mu \mathrm{m}$ wire mesh to remove larger pieces of undissociated tissue. The flow-through was centrifuged at $250 \times g$ for $5 \mathrm{~min}$, after which the supernatant was aspirated and the pellet resuspended DMEM/F12. After additional trituration, the suspension was filtered through a $40 \mu \mathrm{m}$ cell strainer to remove nondissociated cell aggregates. Cell fractions from each of the filtrates and flow-through steps were cultured in DMEM/F12 plus 10\% FBS (DMF/10) supplemented with fungizone and penstrep, and it was determined that the highest number of ICAM-1+ basal cells was among cells remaining on top of the $40 \mu \mathrm{m}$ cell strainer. These cells were used for initial plating experiments, before the selection of ICAM1-positive cells using magnetic activated bead cell sorting (MACS), and purification using fluorescence-activated cell sorting (FACS).

\section{ICAM-1 (CD54) selection of basal cells}

The culture method used for immunomagnetic selection of basal cells was the same as that used for initial experiments detailed above, except that the post- $80 \mu \mathrm{m}$ suspension was treated in $2 \mathrm{~mm}$ EDTA in PBS for 10 min at $37^{\circ} \mathrm{C}$ to further dissociate cells, to enable more basal cells to pass through the $40 \mu \mathrm{m}$ cell strainer. The single-cell suspension obtained from the 40 micron flow-through was spun at $250 \times g$ for $5 \mathrm{~min}$ and blocked in 2\% FBS in PBS for $10 \mathrm{~min}$ at room temperature to prevent nonspecific binding of primary antibody. The suspension was centrifuged at $250 \times g$ for $5 \mathrm{~min}$, the supernatant aspirated, and the cells incubated with a 1:100 dilution of biotinylated anti-ICAM-1 (CD54) antibody (PharMingen) in PBS for 30 min on ice. The cells were washed twice in 2 mM EDTA/PBS and incubated with MACS streptavidin microbeads (Miltenyi Biotec, Auburn, CA) for $20 \mathrm{~min}$ at $4^{\circ} \mathrm{C}$. Labeled cells were separated using a MACS magnetic separator separation column (Miltenyi Biotec) placed in the magnetic field of the MACS stand (Miltenyi Biotec). The yield of CD54-positive, -negative, and unsorted fractions (taken before sorting) was then determined using a hemocytometer. For clonal density plating, cells were plated at 6000 cells per $10 \mathrm{~cm}$ Petri dish $\left(75\right.$ cells $\left./ \mathrm{cm}^{2}\right)$. Standard plating medium was DMF/10 supplemented with fungizone and penstrep $(2.5 \mathrm{mg} / \mathrm{ml}$ and $100 \mathrm{mg} / \mathrm{ml}$, respectively; Invitrogen). The standard coating substrate was rat tail collagen, a 
source that contains primarily type I collagen ( 5 $\mu \mathrm{g} / \mathrm{cm}^{2}$; Roche). Cells were incubated at $37^{\circ} \mathrm{C}$ with $5 \% \mathrm{CO}_{2}$ for 2 weeks, at which point small, medium, and large colonies were counted. Cloning efficiencies were determined by dividing the total number of total colonies by the number of cells initially plated.

\section{Fluorescence-activated cell sorting}

The olfactory epithelium of P5 mice was dissected and digested as described for the magnetic-activated cell sorting. After filtering through an $80 \mu \mathrm{m}$ wire mesh, the suspension was centrifuged at $310 \times g$ for $5 \mathrm{~min}$ and then incubated in $2 \mathrm{~mm}$ EDTA in PBS on ice for 10 $\min$. The cells were then centrifuged at $310 \times g$ for 5 min and resuspended in 10\% FBS in PBS at a concentration of $10^{6}$ cells/uL for staining with monoclonal antibodies. The cells were then incubated in the dark on ice for 20 min with 7 -aminoactinomycin D (7-AAD; $20 \mu \mathrm{g} / \mathrm{ml}$; Molecular Probes), R-phycoerythrin (R-PE)conjugated anti-ICAM-1 (CD54) monoclonal antibody $(20 \mu \mathrm{g} / \mathrm{ml}$; BD Biosciences, Mississauga, Ontario, Canada), and fluorescein isothiocyanate (FITC)-conjugated anti-Integrin $\beta_{1}$ (CD29) monoclonal antibody $(20 \mu \mathrm{g} / \mathrm{ml}$; Santa Cruz Biotechnology). The cells were washed twice and resuspended at a concentration of $2 \times 10^{6}$ cells $/ \mathrm{ml}$ and passed through a 40 $\mu \mathrm{m}$ filter immediately before sorting on a Becton Dickinson (San Jose, CA) FACSVantage. Sorted cells were first examined according to size and complexity using forward scatter and side scatter to eliminate debris and then gated for 7-AAD exclusion to eliminate dead cells. They were then sorted for ICAM-1 (R-PE) positivity or ICAM- 1 and $\beta_{1}$-integrin (FITC) double positivity. The purified cells were then cultured as described for the MACS isolated cells.

\section{Test conditions for optimizing cloning efficiency}

Media. Alternative media tested for effect on cloning efficiency included Opti-MEM supplemented with 4\% FBS, keratinocyte serum-free media (K-SFM), DMEM/F12 supplemented with N2, and RPMI supplemented with 10\% FBS (all media and supplements are from Invitrogen). All media conditions were supplemented with fungizone and penstrep.

Growth factors tested were used to supplement Opti-MEM/4\% FBS: EGF (10 ng/ml; Roche), TGF $\alpha$ ( $0.5 \mathrm{ng} / \mathrm{ml}$; Sigma), and leukemia inhibitory factor (LIF) $(20 \mathrm{ng} / \mathrm{ml}$; Sigma), individually and in combination.

Extracellular matrix (ECM) tested for cloning efficiencies of CD54positive cells: $10 \mathrm{~cm}$ dishes or four-chambered slides were coated with collagen ( $5 \mu \mathrm{g} / \mathrm{cm}^{2}$; Roche), laminin ( $3 \mu \mathrm{g} / \mathrm{cm}^{2}$; Roche), fibronectin (5 $\mu \mathrm{g} / \mathrm{cm}^{2} ;$ Roche), and laminin/collagen and fibronectin/collagen combinations. The concentrations of collagen, fibronectin, and laminin used for the substrate mixture experiments were as follows: $3.4 \mu \mathrm{g} / \mathrm{cm}^{2}$ collagen and $1 \mu \mathrm{g} / \mathrm{cm}^{2}$ laminin (2 collagen:1 laminin), $1.7 \mu \mathrm{g} / \mathrm{cm}^{2}$ collagen and $2 \mu \mathrm{g} / \mathrm{cm}^{2}$ laminin (1 collagen:2 laminin), $3.4 \mu \mathrm{g} / \mathrm{cm}^{2}$ collagen and $1.7 \mu \mathrm{g} / \mathrm{cm}^{2}$ fibronectin, and $1.7 \mu \mathrm{g} / \mathrm{cm}^{2}$ collagen with $3.3 \mu \mathrm{g} / \mathrm{cm}^{2}$ fibronectin.

\section{Assessment of adhesion kinetics}

CD54-positive cells were plated at high density (between $7.5 \times 10^{4}$ and $1.1 \times 10^{5}$ cells per well) in DMF/10 onto six-well tissue culture plates coated with collagen, laminin, and fibronectin. Media from these wells were removed after 4 or $24 \mathrm{hr}$ (one time point per well), wells were washed three times in PBS, and nonadherent cells were counted with a hemocytometer.

\section{Immunocytochemistry}

Cells were fixed for $10 \mathrm{~min}$ in $4 \%$ paraformaldehyde, permeabilized in $0.1 \%$ Triton X-100 for $15 \mathrm{~min}$, and blocked in $4 \%$ normal serum for 30
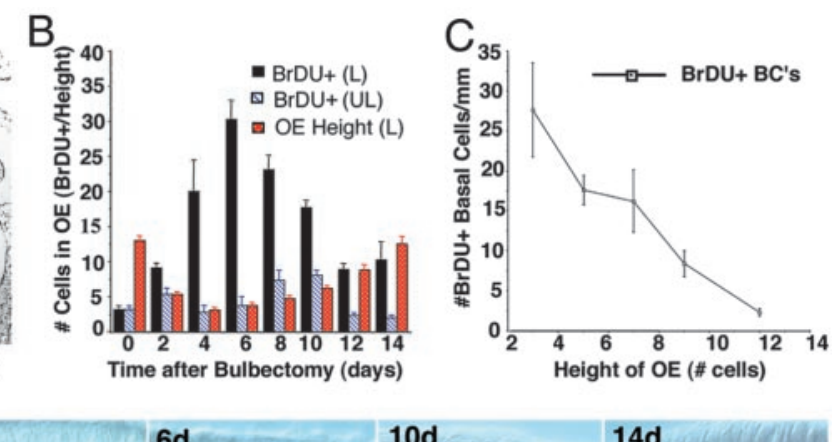

$10 d$

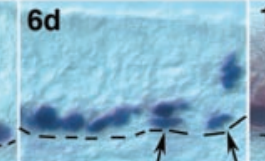

$14 d$

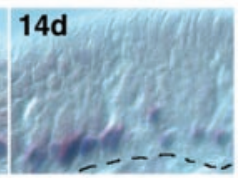

Figure 1. Basal cell mitosis after bulbectomy drives neurogenesis in the $0 \mathrm{E}$. $A$, After bulbectomy, cells in the basal cell layer take during neurogenesis, predominantly on the side ipsilateral to the lesion (6d Lesioned). Three different points within 0.01) mitotic response is also seen on the side contralateral to the lesion (BrDU $+U L)$ by $10 \mathrm{~d}$ postbulbectomy when tomy in evenly spaced GBCs. Basal cell BrDU uptake expands from 2 to $14 \mathrm{~d}$ broadly within the $\mathrm{GBC}$ layer to also include rarely all cells (arrow) on the basal lamina at the peak of neurogenesis ( $6 \mathrm{~d}$ postbulbectomy).

min before an incubation in primary antibody for $12-18 \mathrm{hr}$ at $4^{\circ} \mathrm{C}$. After washes in PBS, the cells were then incubated in the appropriate fluorescently conjugated secondary antibody for $1 \mathrm{hr}$ at room temperature. Before coverslipping in vectashield (Vector Laboratories), the cells were treated with the nulear counterstain $4^{\prime}, 6^{\prime}$-diamidino-2-phenylindole (DAPI; Roche). All images were visualized with an Axioskop 2 MOT microscope (Jena GER; Zeiss, Thornwood, NY) using a SPOT camera (Diagnostic Instruments, Sterling Heights, MI) with Northern Eclipse software (Empix Imaging, Mississauga, Ontario, Canada) and were compiled using Adobe Photoshop 6.0 (Adobe Systems, San Jose, CA).

\section{Results}

Both globose and horizontal basal cells undergo mitosis during ORN genesis in response to the loss of mature ORNs In rodents, surgical removal of the ORN target, the olfactory bulb (bulbectomy), induces a retrograde wave of apoptosis of mature ORNs within $72 \mathrm{hr}$ of lesion (Cowan et al., 2001), stimulating mitosis in local progenitors. In a pattern that has been suggested to recapitulate developmental olfactory neurogenesis, 8-10 million neurons are generated from these progenitors by 2-3 weeks after bulbectomy (Costanzo and Graziadei, 1983; Schwob et al., 1992). The replacement of ORNs in the adult OE after lesion is reported to result from the division of globose basal cells, horizontal basal cells, or a combination of both (Graziadei and Graziadei, 1979b; Caggiano et al., 1994; Schwob et al., 1994). Most of these studies have examined OE neurogenesis at a single site in the OE (e.g., the nasal septum), but clearly ORN replacement is not uniform (Weiler and Farbman, 1997). In fact, it appears to be governed by a balance between the loss rate of mature ORNs (demand for replacement) and the degree of readiness of the local endogenous progenitor population (active vs quiescent). Given that either in the steady state or after lesion, ORN loss does not occur uniformly in all regions of the OE concurrently (Cowan et al., 2001), we first determined whether the temporal and spatial pattern of the initial wave of ORN neurogenesis does relate directly to the loss of only the mature ORN population.

The number of BrDU+ cells per linear millimeter of lesioned 
or unlesioned $\mathrm{OE}$ was assayed at three distinct sites within the OE: (1) OE within a dorsal ecto-turbinate, (2) OE lying along the septal midline, and (3) OE within a ventromedial endo-turbinate (Fig. 1A). In each ipsilateral turbinate assessed at any time, 12-20 cell stretches of actively dividing basal cells (BrDU+ cells) were found adjacent to quiescent (BrDU-negative) basal cell zones. Temporally, the number of BrDU+ cells found per linear millimeter of OE revealed a number of distinct patterns on both the lesioned and unlesioned sides of the OE (Fig. $1 B$ ). First, the peak of proliferation on the lesioned side of the OE occurred at $6 \mathrm{~d}$ postbulbectomy but continued in isolated adjacent patches for several more days. In addition, a significant later increase in $\mathrm{BrDU}+$ basal cells was also seen on the side of the $\mathrm{OE}$ contralateral to lesion $(p<0.01)$, with the majority of the contralateral $\mathrm{BrDU}+$ cells lying in OE situated along the septum, at $8-10 \mathrm{~d}$ postbulbectomy.

In each individual turbinate examined, there was a clear inverse relationship between the number of proliferating basal cells per linear millimeter and the number of cells above the basal cell layer within the same millimeter of $\mathrm{OE}$ (Fig. 1C). Cells within the OE above the basal cell layer at any time are a mixture of immature neurons, ORNs, and sustentacular cells, but the postbulbectomy stimulation of neurogenesis has been attributed primarily to a need to replace the lost mature, OMP-positive ORNs (Cowan et al., 2001). After close examination of the mitotic basal cells, the earliest cells to become BrDU+ (at $2 \mathrm{~d}$ postbulbectomy in each turbinate assessed) were in the GBC compartment, situated directly on top of the flattened $\mathrm{HBC}$ layer, and were spatially separated by defined $6-10$ cell lateral intervals (Fig. $1 D$ ). From 4-8 d postbulbectomy, $96-98 \%$ of $\mathrm{BrDU}+$ cells of the $\mathrm{OE}$ were in the globose basal cell compartment, with rare BrDU + cells also arising in the HBC population. After the initial peak of proliferation ( $6 \mathrm{~d}$ postbulbectomy), widespread proliferation of GBCs continued until 10-14 d postbulbectomy. GBC progeny could be seen migrating to a more superficial $\mathrm{OE}$ layer, whereas flattened BrDU+ horizontal basal cells were rare and even more rarely appeared to leave the HBC layer, causing a disruption in this normally continuous layer (Fig. 1D). The behavior of GBCs after bulbectomy (dividing rapidly in a neurogenic response) is consistent with the hypothesis that the majority of GBCs may represent a rapidly dividing transit amplifying population or more committed progenitor (Potten and Loeffler, 1990; Watt, 2001). HBCs, in contrast, divide rarely, even at the peak of neurogenesis, similar to stem cells of non-neural systems. We thus tested whether any cells in the HBC layer may display additional biological distinguishing characteristics in vivo that may resemble potential stem cells from beyond the nervous system.

\section{Do HBCs resemble cells found in other stem cell niches?}

In the stem cell niches of the epidermis, colon, and bone marrow, cell adhesion molecules, especially integrins, act in concert with growth factors to control differentiation and proliferation of more primitive progenitors and stem cells (Sastry and Horwitz, 1996; Watt, 2002). Similar adhesion-dependent mechanisms may be used by putative NSCs to regulate a stem cell phenotype, but this has not been tested in a readily identifiable in vivo candidate quiescent NSC pool, especially as most have been tested in a nonadherent (neurosphere) state. We thus tested whether HBCs in the quiescent OE may express adhesion receptors more commonly found in non-neural quiescent stem cell populations that may regulate their ability to respond to environmental signals to inhibit their differentiation and promote quiescence.
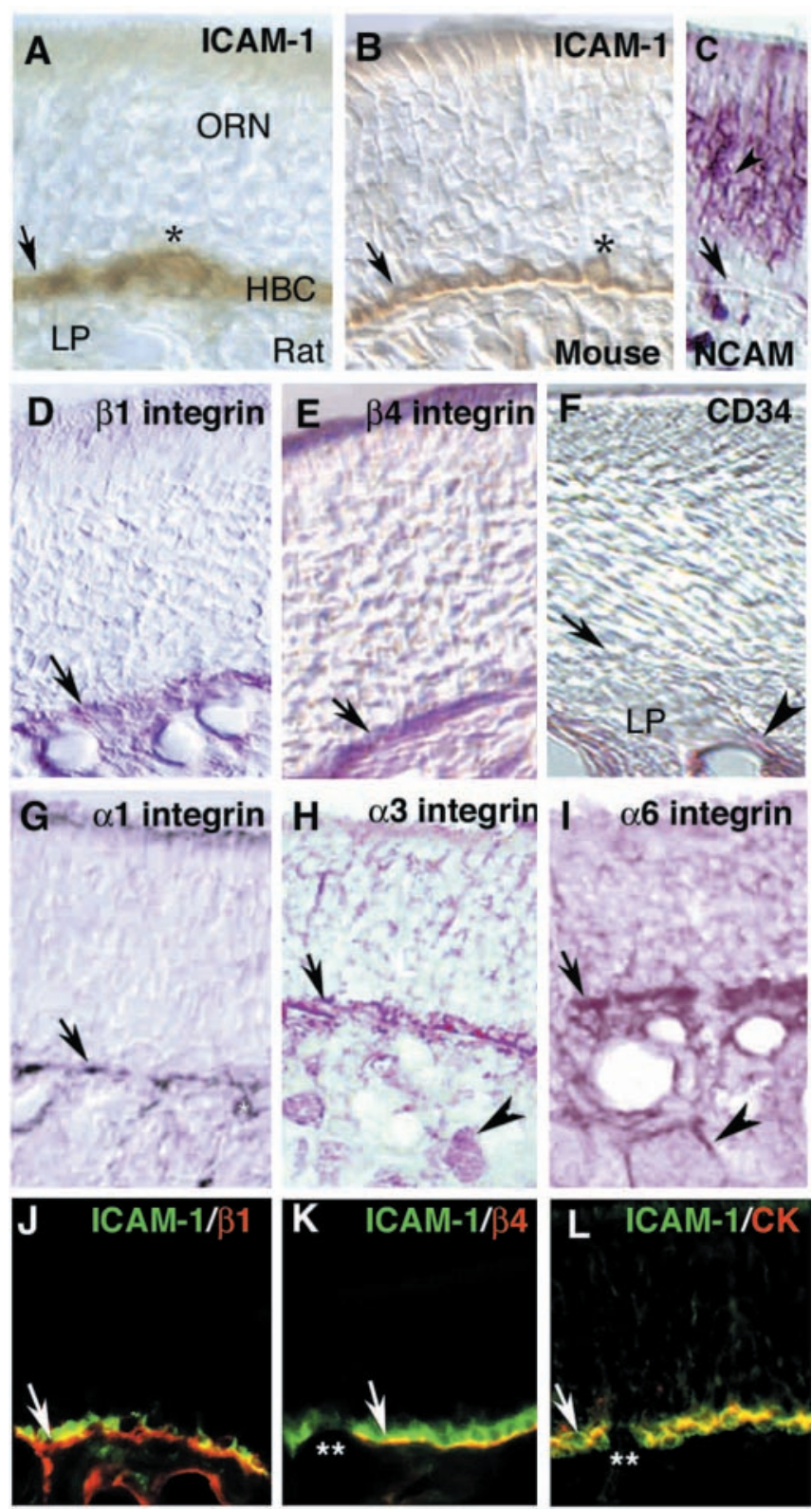

Figure 2. Adhesion receptor expression in horizontal basal cells. $A, B$, The ICAM-1 is exclusively expressed (arrow) in the $\mathrm{HBC}$ population of rat $(A)$ and mouse $(B)$ but not in the globose basal cell layer $\left({ }^{*}\right)$ or ORNs, using DAB immunohistochemistry. In the 0 E proper (above the basal lamina), the NCAM ( $C$; VIP immunohistochemistry) is restricted to the neuronal population (ORN) and is excluded from basal cells (arrow points to $\mathrm{HBC}$ layer in all images). $D-F, \beta_{1}$ Integrin $(D)$ and $\beta 4$ integrins $(E)$ are also expressed chiefly by $H B C s$ that $(F)$ do not express the stem cell marker CD34 (arrow), which is found only on blood vessels in the lamina propria (LP; arrowhead). $\mathrm{HBC}$ (arrows) also express $\alpha_{1}$ integrin ( $G$ ) on their basal surface where they adhere to the basal lamina $\alpha_{3}$ integrin $(H)$, which is also found in some mesaxon bundles (arrowhead), and $\alpha_{6}$ integrin $(I)$, which is also expressed by periaxonal olfactory ensheathing cells (arrowhead) of the lamina propria. $J-L$, By double immunofluorescence, basal cell ICAM-1 expression (green) coincides on the HBC basal membrane (becoming yellow) with $\beta_{1}$ integrin (J, red), $\beta 4$ integrin $(K$, red), and also cytokeratin 903 (CK; $L$, red). Eruptions in the basal membrane caused by glandular ducts are indicated $(* *)$.

In the quiescent OE, ICAM-1 (recognized by CD54) is expressed continuously on the basal, lateral, and to a lesser extent apical membranes of HBCs of both rat and mouse (Fig. $2 A, B$ ). In contrast, the cell adhesion molecule more characteristic of neurons, NCAM (recognized by CD56), is not detected on HBCs but is strongly expressed in cells above these in the GBC and neuronal 
Table 1. Developmental expression profiles of cells in the olfactory epithelium

\begin{tabular}{|c|c|c|c|c|c|c|c|c|c|c|c|c|c|c|c|}
\hline Cell type & $0 M P$ & NST & Mash-1 & $G B C-2$ & ICAM-1 & $\beta_{1}$ & $\beta_{4}$ & $\alpha 1$ & $\alpha 3$ & $\alpha 4$ & $\alpha 6$ & CD34 & CD43 & CD44 & Nestin \\
\hline ORN & + & \pm & - & - & - & - & - & - & - & - & \pm & - & - & - & - \\
\hline IRN & - & + & - & \pm & - & - & - & - & - & - & \pm & - & - & - & - \\
\hline $\mathrm{GBC}$ & - & \pm & \pm & + & - & - & - & - & - & - & - & - & - & - & - \\
\hline $\mathrm{HBC}$ & - & - & - & - & + & + & + & + & + & - & + & - & - & - & - \\
\hline OEC & - & - & - & - & - & + & - & - & - & \pm & + & - & - & \pm & \pm \\
\hline $\mathrm{Mac}$ & - & - & - & - & - & - & - & - & - & - & - & - & + & + & - \\
\hline Endoth & - & - & - & - & \pm & - & - & - & - & - & - & + & - & + & - \\
\hline Sus & - & - & - & - & - & - & + & \pm & \pm & + & - & - & - & - & \pm \\
\hline BGs & - & - & - & - & - & - & \pm & - & + & - & - & - & - & - & - \\
\hline
\end{tabular}

Antigens are scored as either being negative $(-)$, positive $(+)$ in the quiescent $0 \mathrm{E}$, or variable $( \pm$ ) depending on a change in state. (ell types are ORN (olfactory receptor neuron), IRN (immature receptor neuron), GBC ( globose basal cell), HBC (horizontal basal cell), OEC (olfactory ensheathing cell), Mac (macrophages), Endoth (endothelial cells), and Sus (sustentacular cells); data are summarized from this study and Schwob (2002).

layers of the $\mathrm{OE}$ (Fig. 2C). The $\beta_{1}$ integrin subunit (CD 29) is found on HBCs where their basal membrane is closely apposed to the basal lamina separating the OE proper from the lamina propria (Fig. $2 D, J$ ). A similar distribution is detected for the $\beta_{4}$ integrin subunit (CD 104), which is found on the basal surface of HBCs where they attach to the basal lamina (Fig. 2E, K). CD 34, which recognizes the mucosialin antigen and is widely expressed on hematopoietic progenitors, is not expressed on any cell type within the OE proper but is expressed on endothelia of the lamina propria (Fig. $2 F$ ).

$\beta$-Integrins complex with a range of $\alpha$ subunits to form active heterodimers, which interact with secreted proteins of the extracellular matrix (Hynes, 1992; Watt, 2002). We detected expression of $\alpha_{1}$ integrin (CD49a), $\alpha_{3}$ integrin (CD49c), and $\alpha_{6}$ integrin (CD49f) on some HBCs in vivo, with expression again segregated primarily to the basal surface of the cell (Fig. 2G-I, respectively). $\alpha_{3}$ Integrin was also expressed on subsets of axons within axon bundles of the lamina propria, and $\alpha_{6}$ integrin was expressed on the processes of cells on the periphery of axon bundles, which are likely olfactory ensheathing cells (OECs) (Ramon-Cueto and Avila, 1998). $\alpha_{2,4,5}$ Integrins were not detected on any basal cells in vivo but were detected in positive control tissue (data not shown).

Double immunofluorescence revealed that in the quiescent OE, ICAM1 is coexpressed in HBCs with $\beta_{1}$ integrin (Fig. $2 J$ ). ICAM- 1 and $\beta_{4}$ integrin are also coexpressed, but both $\beta_{1}$ and $\beta_{4}$ are restricted primarily to the basal membrane of HBCs (Fig. $2 \mathrm{~K}$ ); HBC expression was also confirmed by ICAM-1 coexpression with the accepted HBC marker, cytokeratin (keratin 903) (Fig. 2L) (Suzuki and Takeda, 1993). The heterophilic ICAM-1 ligands Mac-1 (CD11) and leukocyte function antigen-1 are not expressed by OE basal cells or cells adjacent to them in the normal (unlesioned) OE, although Mac-1 (CD11) is expressed by infiltrating macrophages involved in the repair process of the OE after lesion (data not shown). These data have allowed us to significantly expand the reference set of neuronal, glial, and extracellular matrix receptors that antigenically distinguish cells belonging to the different lineages within the $\mathrm{OE}$ and lamina propria, including HBCs (Table 1).

Laminin is highly expressed in the periphery of olfactory nerve fascicles but is concentrated in the olfactory basal lamina between the $\mathrm{OE}$ and the lamina propria, demonstrating the close association between the basal lamina and continuous layer of ICAM-1+ HBCs (BL) (Fig. 3A,D), with minor interruptions only where Bowman's glands pierce into the OE. In contrast, HBC expression of the laminin ligand, $\beta_{1}$-integrin, is not uniform but segregated in zones of alternating high-expressing and low-expressing HBCs (Fig. 3E). A similar pattern is seen for HBCs strongly ex-
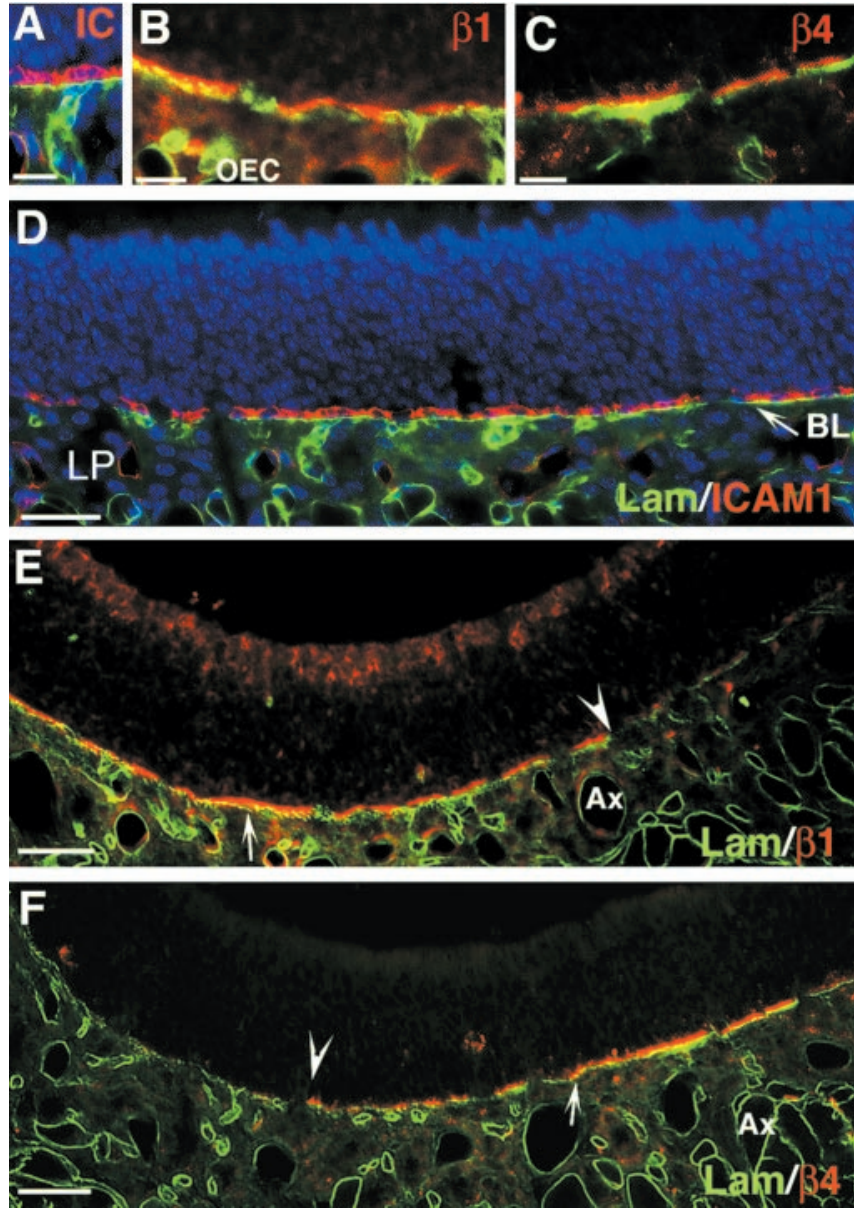

Figure 3. $\beta_{1}$ and $\beta_{4}$ integrins adhere $H B C$ s to specific zones of olfactory epithelium basal lamina. $A, D, H B C$ expressing ICAM-1 $(A$, red) on their lateral and basal surface sit directly on a laminin-rich (green) basal lamina and are, at lower power $(D)$, evenly distributed across the basal lamina (BL) of the $O E$. In contrast, $\beta_{1}$ integrin ( $B$, red) is expressed only on the basal membrane of $H B C$ s in direct contact with the laminin-rich (green) basal lamina (areas of direct contact are yellow), which is secreted by OECS of the lamina propria (LP).E, HBCs with high $\beta_{1}$-integrin expression (red) define specificzones of the $0 \mathrm{E}$, which are flanked by stretches of $\mathrm{HBCs}$ that are mostly $\beta_{1}$ negative. Boundary between these zones is marked with white arrowhead, under which are located the laminin-rich OEC ensheathments of ORN axon bundles (Ax). C, Similarly, HBCs localize $\beta_{4}$ integrin (red) to their basal membrane where they are tightly bound to the basal lamina (green) and, at lower power, are distributed in highexpressing and low-expressing zones ( $F$, separated by arrowhead) along the laminin-rich (green) basal lamina. Scale bars: $A-C, 10 \mu \mathrm{m} ; D-F, 50 \mu \mathrm{m}$.

pressing the ECM receptor, $\beta_{4}$-integrin (Fig. $3 F$ ). These data suggest that, similar to basally situated epidermal stem cells, complexes of specific $\alpha$ and $\beta$ integrins and cell adhesion molecules may define the cellular environment in which HBCs preferen- 

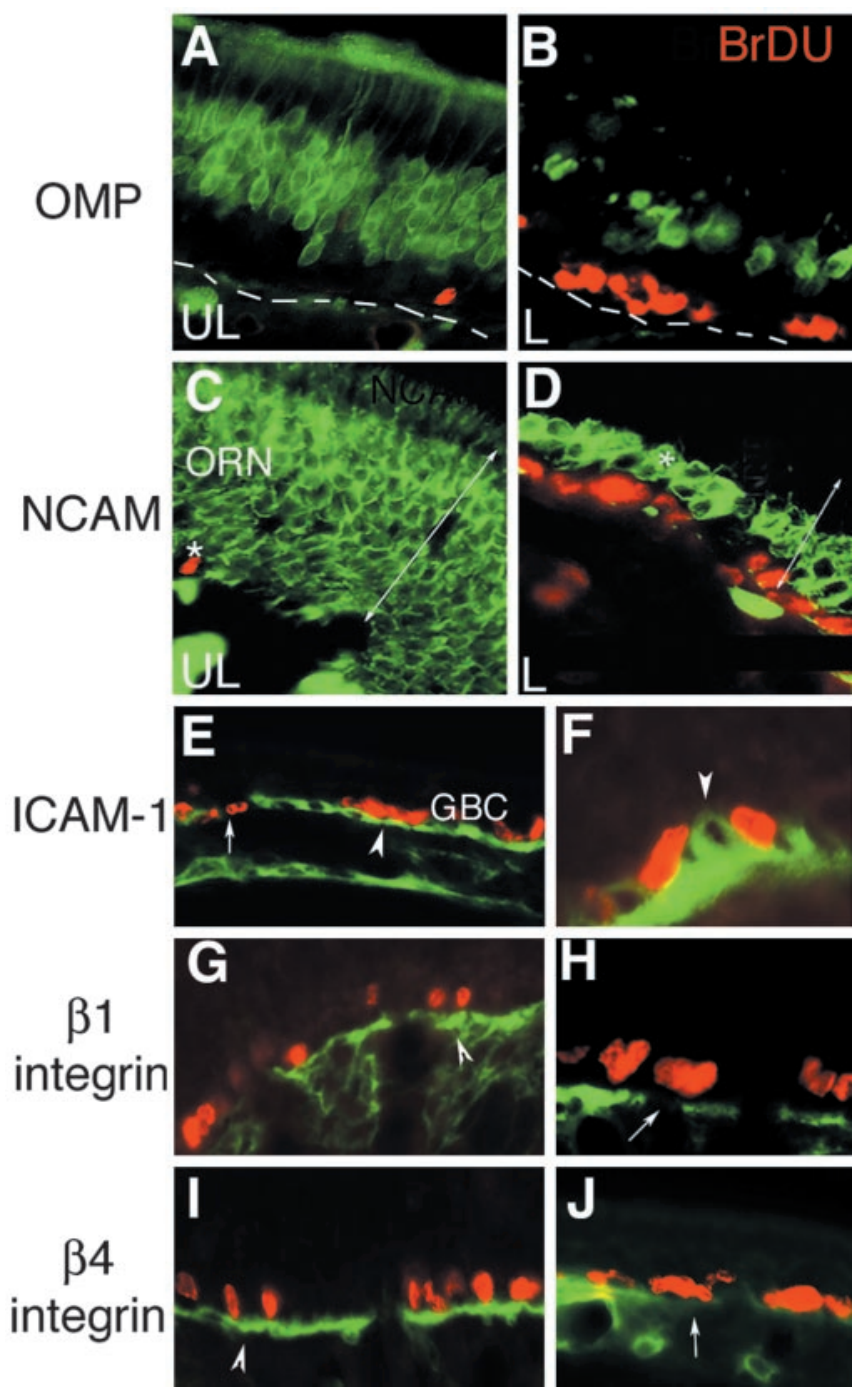

Figure 4. Loss of the mature ORN population stimulates basal cells to lose adhesion receptor expression as they undergo mitosis. The unlesioned (UL) OE contains a robust population of OMP + ORNs ( $A$, green), NCAM+ neurons ( $C$ ), and rare, dividing, BrDU + globose basal cells (red). Double-headed arrows indicate the thickness of the $0 \mathrm{E}$. The basal lamina is indicated with a dotted line. $B$, The $0 \mathrm{E}$ at $4 \mathrm{~d}$ after bulbectomy $(\mathrm{L})$ has a vastly reduced sporadic $0 \mathrm{MP}+$ population (green) and exhibits robust BrDU uptake (red) in the basal cell layer. C, In unlesioned OE, NCAM (green) is expressed in immature and mature ORNs but excluded (*) from a zone of cells around dividing (red) basal cells. D, After bulbectomy, this layer immediately above the $\mathrm{BrDU}+($ red) basal cells becomes an NCAM + immature receptor neuron population (green). $E$, Where GBCs become BrDU+ (red), adjacent HBCs (arrowhead) strongly express ICAM-1 (green). Where flattened nuclei of $\mathrm{HBC}$ become BrDU+ (red, arrow) and prepare to leave the basal lamina, ICAM-1 expression is lost. F, At higher power, loss of lateral ICAM-1 expression by $\mathrm{BrDU}+\mathrm{HBC}$ is more evident, whereas ICAM-1 expression is increased in neighboring BrDUnegative $H B C s$ (green, arrowhead). $G$, Similarly, where cells of the globose basal cell layer are $\mathrm{BrDU}+(\mathrm{red})$, adjacent $\mathrm{HBC}$ on the basal lamina clearly express $\beta_{1}$ integrin $(G$, green, arrowhead), and flattened $\mathrm{HBC}$ s lose $\beta_{1}$ expression as they take up $\mathrm{BrDU}$ and prepare to leave the basal lamina $(H) . I, J, \beta_{4}$ integrin expression (I, green, arrowhead) is similarly upregulated on the basal surface of $\mathrm{HBC}$ adjacent to BrDU $+\mathrm{GBC}$ s adherent to the basal lamina and is lost as these cells take up BrDU, become mitotic (J, red, arrow) and leave the basal lamina.

tially adhere and quiesce, and that integrin activation by the appropriate basal lamina ECM may similarly negatively regulate HBC mitosis and differentiation (Watt, 2002). It is thus important to assess the stability of $\mathrm{HBC}$ adhesion receptor expression in a nonquiescent environment, when mitosis and neurogenesis are maximally stimulated.
$\mathrm{HBC}$ integrin expression is disrupted in mitotic HBCs during olfactory neurogenesis

In the normal (quiescent) $\mathrm{OE}, \mathrm{BrDU}+\mathrm{GBCs}$ (directly above the HBC layer) can be readily detected in regions of the unlesioned $\mathrm{OE}$ that appear to have a full complement of OMP + ORNs and $\mathrm{NCAM}+$ immature receptor neurons (IRNs)/ORNs (Fig. 4A, C). However, the loss of $>90 \%$ of the mature OMP + ORN population by $6 \mathrm{~d}$ after bulbectomy stimulates widespread mitosis in both GBCs and HBCs (Fig. 4B). The first wave of neurogenesis is also accompanied by the immediate expression of NCAM by a normally NCAM-negative population of developing ORNs immediately above GBCs (Fig. 4D).

At the initiation of basal cell mitosis, the continuous high expression of ICAM-1, and $\beta_{1}$ and $\beta_{4}$ integrins adjacent to the basal lamina became disrupted and discontinuous (Fig. $4 E-J$ ). By $6 \mathrm{~d}$ after bulbectomy, rare BrDU+ nuclei of presumptive HBCs (identifiable by distinct, flattened BrDU + nuclei in close apposition to the basal lamina) were most frequently ICAM-1 negative. In contrast, where clusters of GBCs appeared BrDU positive, ICAM-1 expression was readily detected in adjacent HBCs (Fig. $4 E$, arrow). ICAM-1 expression was not detectable in mitotic cells as they exited the basal cell layer but was strongly expressed in groups of adjacent, BrDu-negative HBCs (Fig. $4 F$, arrowhead). A similar response was seen for both $\beta_{1}$ (Fig. 4G, $H$ ) and $\beta_{4}$ integrins (Fig. $4 I, J$ ), where HBC mitosis was accompanied by a decrease and disruption of integrin expression in regions of localized BrDU+ mitotic HBCs and a comparative increase in detectable expression of integrin expression in adjacent BrDU-negative HBCs. Thus, it appears that, similar to epidermal stem cells, the expression of each adhesion receptor is downregulated in dividing nonquiescent $\mathrm{HBCs}$ during olfactory neurogenesis and retained in HBCs committed to remaining on the basal lamina (Adams and Watt, 1990; Zhu et al., 1999).

\section{Do HBCs display an in vitro progenitor phenotype?}

Collectively, the in vivo expression of adhesion receptors and their concomitant changes during neurogenesis suggests that, of all the cells of the OE, some horizontal basal cells have an interchangeable quiescent and active phenotype similar to stem cells from other systems. This is most evident during the early postnatal phase of olfactory neurogenesis at P5 where, although ICAM$1+/ \beta_{1 / 4}$ integrin-positive cells are already arranged along a laminin-rich basal lamina (Fig. $5 A$ ), some regions contain areas of ICAM-1-positive HBC doublets aligned perpendicular to the basal lamina (Fig. $5 B$ ), whereas others demonstrate compacted regions of restricted ICAM-1/ $\beta-4$ expression (Fig. $5 C$ ). At P5, many zones of $\mathrm{OE}$ are highly expanded (Fig. $5 D$ ) and contain ICAM-1+/cytokeratin + cells within regions of high PCNA expression that appear to represent ongoing progenitor mitosis (Fig. $5 E, F)$.

Because the P5 OE contains extensive populations of HBCs that are both actively mitotic and apparently quiescent, we established culture conditions that allowed us to promote retention of these phenotypes in vitro, to test whether cells antigenically resembling HBCs were capable of forming adherent colonies similar to those generated from other stem cell-containing systems. Because OE basal lamina is also rich in collagen during development (Julliard and Hartmann, 1998) and integrin receptors for collagen are highly expressed on HBCs in vivo (Figs. 2-4), we initially used a mixed collagen substrate for all initial colonyforming adhesion assays. We first refined cell fraction selection by size and adherence from dissected $\mathrm{OE}$ and tested colony formation on successive dilutions of cells. In this way, we identified 

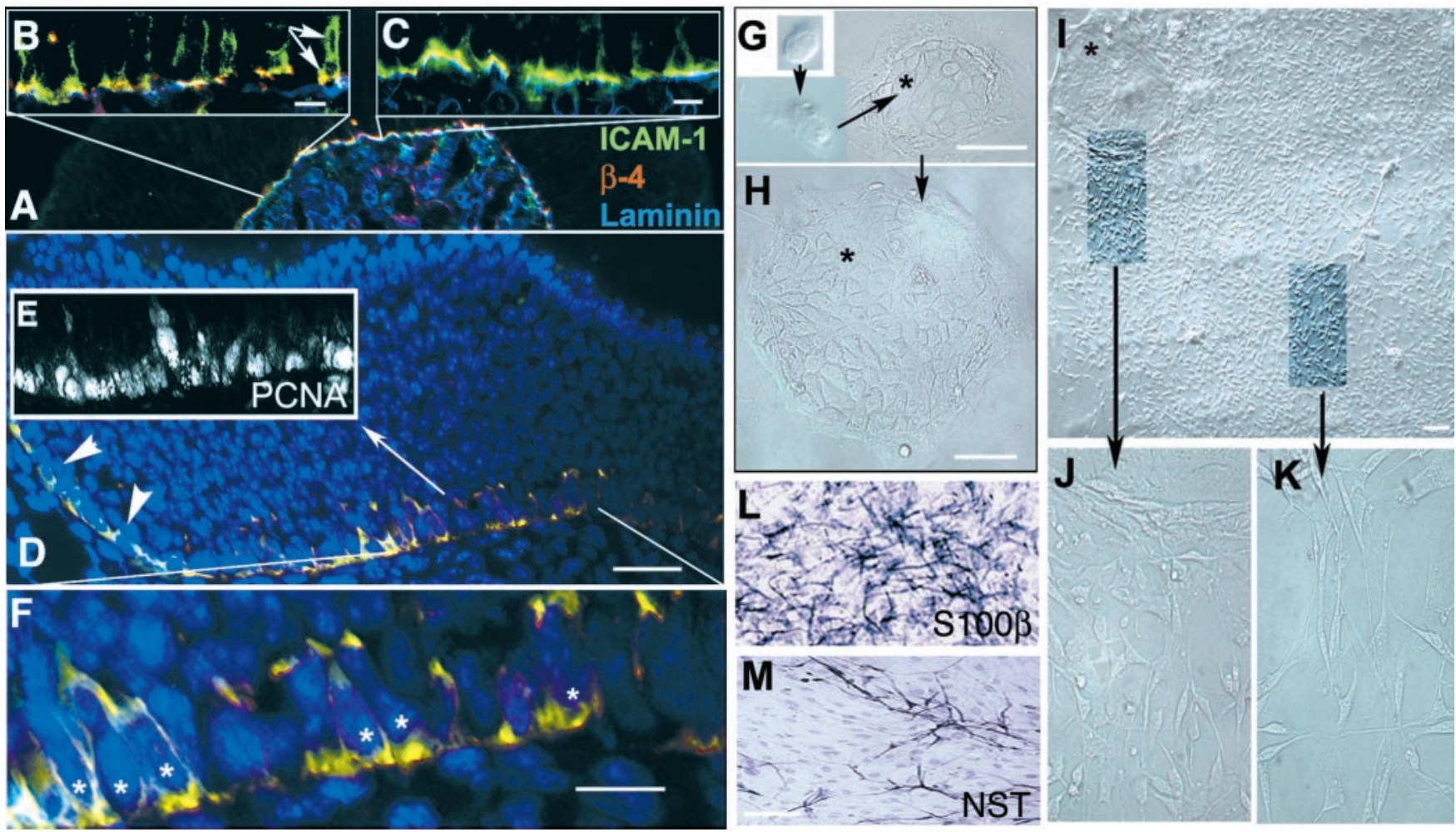

Figure 5. Cells from the ICAM-1-rich fraction of 0 E form highly adhesive clonal colonies and produce differentiated neurons and glia in vitro. $A$, At P5, the HBC layer contains ICAM- 1 (green) $/ \beta_{4}$ integrin (red)-rich cells on a laminin-rich (blue) basal lamina. B, ICAM-1 HBCs are dividing in a direction perpendicular to the basal lamina (double arrow), where one daughter contains $\beta_{4}$ integrin (red) and the other does not. C, Some regions contain HBC with ICAM- 1 and $\beta_{4}$ expression primarily restricted to the basal surface. $D-F$, The ICAM-1+ (green)/cytokeratin + (red) is a small percentage of the total population (DAPI; blue) but represents the majority of $\mathrm{PCNA} /$ Ki67-positive cells $(E)$ that are clearly undergoing mitosis $\left({ }^{*}\right.$ on $\mathrm{HBC}$ of origin) in a plane perpendicular to the basal lamina (F). An ICAM-1+-rich/NCAM-negative cell fraction prepared from the neonatal mouse 0 E was subsequently dissociated into single cells and plated at clonal density on a collagen matrix in DMEM/F12 with $10 \%$ fetal calf serum. G, Single cells ( ${ }^{*}$ marks the same cell position followed over time in vitro) of this cell fraction expanded rapidly over 7 DIV to form small, tightly adhesive colonies. H, Colony expansion continued from 7 to 14 DIV to produce colonies containing 25-40,000 cells (medium-large colony shown here). C, At 14-28 DIV, the larger colonies (colony marked with * in top left-hand corner) produced multiple differentiated progeny $(I-K)$ (bipolar and multipolar), which usually migrated away from the edge the colony. $J$ begins at the edge of the original colony boundary. In some instances, differentiated progeny arose from the center of the colony and migrated along the more adhesive colonies beneath. $L, M$, Cells of both glial $(L)(S 100 \beta+)$ and neuronal (M) (type III $\beta$ neuron-specific tubulin (TuJ1+) phenotypes were represented in migratory cells. Scale bars: B, C, F, $10 \mu \mathrm{m} ; G-M, 50 \mu \mathrm{m}$.

an adherent cell fraction that seeded morphologically defined colonies and generated an in vitro population that was initially assayed as $>80 \%$ HBC-like at $7 \mathrm{~d}$ in vitro (DIV), by cell clustering phenotype and coexpression of ICAM-1 with either $\beta_{1}$ or $\beta_{4}$ integrin on cells in the colony. The most HBC-rich fraction was subsequently plated at clonal density (limiting dilution) to assay for cells that may be more stem-like (capable of forming colonies in isolation). By 7 DIV, the majority of cells $(>90 \%)$ plated from this fraction had not adhered but died, a small percentage $(<7 \%)$ spontaneously differentiated into individual bipolar or multipolar cells, and a consistent percentage (2-3\%) expanded over 7 DIV to form small clusters (4-30 cells) and large clusters (1001000 cells) (Fig. $5 H$ ) by 14 DIV. Most ( $>70 \%$ ) large adherent cell clusters subsequently expanded over 14 DIV into larger adherent colonies up to several thousand cells. A typical colony (with the originating cell position marked with an asterisk) was followed from 1-28 DIV (Fig. 5G-K). Each cluster of cells was marked and examined microscopically every day to confirm their isolation from other colonies. When expanded in 10\% FBS, larger colonies (from 21-28 DIV) produced multiple migratory cells of a more differentiated morphology (Fig. 5I-K) that were later confirmed as representing both neuronal (NST+) and glial $(\mathrm{S} 100 \beta+)$ phenotypes (Fig. $5 L, M$ ).

\section{Cell surface antigen selection of HBCs}

These results suggested either that colony-seeding cells from the OE preferentially generate ICAM-1-positive basal cells in vitro or that ICAM-1 + HBCs themselves may contain subpopulations of cells capable of forming colonies of self-replicating cells with predictable frequency. We hypothesized that by generating conditions that better resemble (at least in part) the $\mathrm{HBC}$ in vivo niche, we may better promote retention of an $\mathrm{HBC}$ in vivo phenotype after cell selection in vitro. We first used a gentle but stringent sorting approach, MACS, to isolate single-cell suspension enriched ( $>90 \%$ enrichment) in ICAM-1+ (CD54+) cells. MACS was used to minimize HBC loss, given that the in vivo adhesion receptor suggested that strongly adherent HBCs may display significant dependence on cell-cell or cell-matrix interactions for survival and could be lost (because of anoikis) (Frisch and Francis, 1994) during the harsher cell processing required for FACS. MACS was followed by clonal density plating of cells on collagen, with cultures marked $24 \mathrm{hr}$ after plating and monitored continuously to ensure that colonies were indeed derived from a single founder cell. This enabled us to test whether ICAM-1-positive HBCs in vitro expand and also whether they continue to express ICAM-1 (CD54) and either $\beta_{1}$ (CD 29) or $\beta_{4}$ (CD104) integrin (or downregulate as they divide or differentiate) in a manner similar to that observed in vivo. 

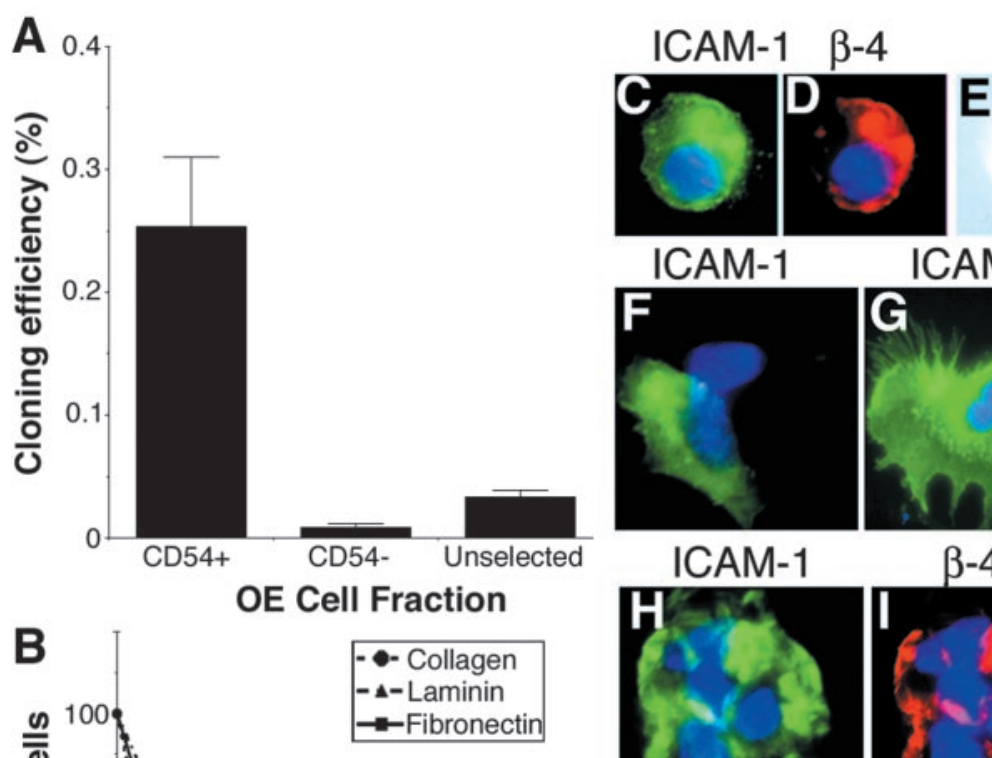

ICAM-1
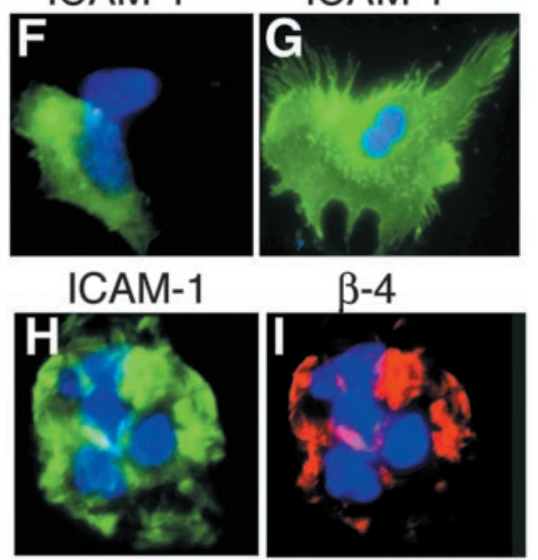

ICAM-1+BrDU

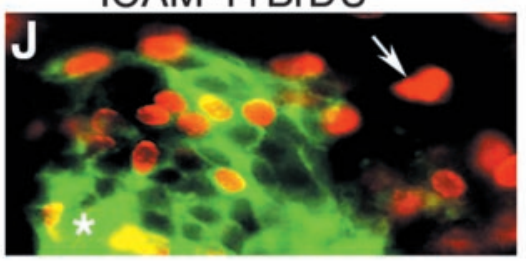

Time (hrs)
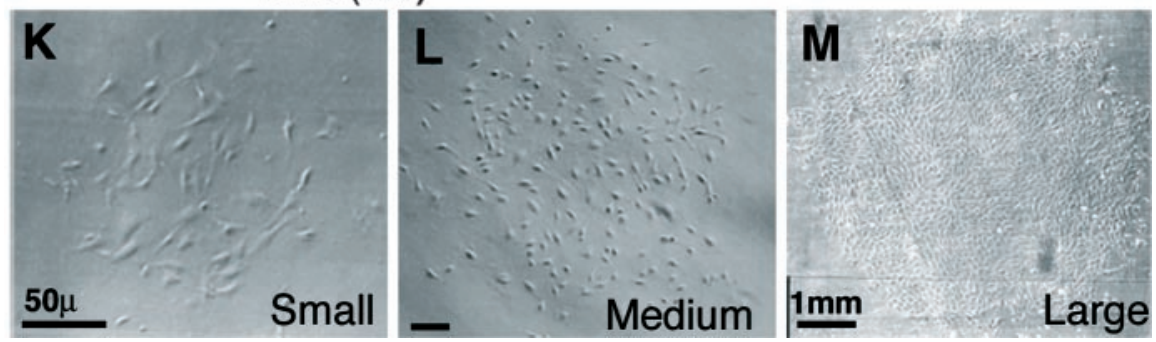

Figure 6. Single-cell selection for ICAM-1 yields a population of horizontal basal cells capable of surviving and expanding at clonal density. ICAM-1+ cells (CD54+) were selected by MACS and plated at clonal density to assay for colony forming ability. $A$, More than $90 \%$ of the colony-forming cells from the 0 E were found in the CD54 + fraction. $B$, An adherence assay revealed that the ICAM-1 + cells preferentially adhered to a collagen matrix, over fibronectin or laminin, within $4 \mathrm{hr}$ of plating. Statistical significance $(n=3)$ was calculated by a Student's $t$ test; ${ }^{*} p<0.0005$. After plating selected CD54+ cells on a collagen matrix, single cells were positive for ICAM-1 (CD54; C, green) and $\beta_{4}$ integrin (CD104; D, red; DAPI stains nuclei blue), where $E$ is the bright-field image for both at 1 DIV. ICAM + cells divide asymmetrically $(F)$ and symmetrically $(G)$ as they expand to first form small colonies that are frequently homogeneously positive for ICAM-1 (CD54; $H$, green) and $\beta_{4}$ integrin (CD104; I, red). As the colonies expand, they become more heterogeneous, with some ICAM-1+ cells (green) concentrated at the core becoming BrDU + in the interior of the colony ( $J$, red; marked with *). Other BrDU + cells on the periphery of the colony are negative for ICAM-1 expression (arrow). At 14 DIV, the colonies can be subdivided into three categories on the basis of size: small, $<30$ cells (K); medium, $30-150$ cells ( $L$ ); and large, $>150$ cells $(M)$. Scale bars: $K, L, 50 \mu \mathrm{m} ; M, 1 \mathrm{~mm}$.

Colony-forming ability at clonal density was initially tested between the ICAM 1-positive and -negative MACS fractions (CD54+/-) and compared with the original unselected cell fraction used for sorting (Fig. 6A). By 14 DIV, 96.8\% of the colonyforming cells from the OE were found in the CD54+ MACSselected fraction, whereas $3.2 \%$ of the CD54-negative cells from this fraction formed colonies, with a baseline cloning efficiency (assayed as the percentage of single cells plated that form colonies) of $0.033 \%$ (Fig. $6 A$ ). To identify the best media in which to test mitogens and growth factors known to influence HBC divi- sion in vivo, we tested DMEM/F12 against a variety of media, including OptiMEM, a medium optimized for low-serum conditions. Serum concentrations ranging from 2 to $10 \%$ were also used. DMF/10 yielded the highest number of colonies, with OptiMem/4\% FBS (Opti4) yielding $72 \%$ of this number. Adherent colony formation from ICAM1 + cells was calcium dependent, because cells did not adhere and form colonies in RPMI (even supplemented with $10 \%$ serum) or K-SFM. Initial adhesion assays on single selected cells confirmed collagen as the single preferred substrate for ICAM-1+ HBCs, given that $78 \%$ of MACSselected CD54+ cells preferentially adhere to a collagen substrate within $4 \mathrm{hr}$ of selection (Fig. 6B).

When assayed by immunofluorescence at 1 DIV after adhesion, $92.3 \%$ of cells adhering to collagen still expressed ICAM-1, whereas only $13.9 \%$ expressed $\beta_{1}$ integrin. After 1 DIV, after adhesion to a collagen substrate, $>80 \%$ of single ICAM- $1+$ cells (Fig. 6C) also continued to coexpress $\beta_{4}$ (Fig. $6 D$ ) with a smaller percentage $(11 \%)$ coexpressing $\beta_{1}$ integrin. Selected ICAM1 -positive cells undergoing mitosis appeared to divide symmetrically and asymmetrically, where ICAM-1 expression was lost in a single daughter (Fig. $6 F$ ) or retained in both daughters as they divided (Fig. 6G). As cells expanded to form circular, symmetrical colonies, coexpression of ICAM- 1 and $\beta_{4}$ integrin was retained in some of the progeny (Fig. $6 H, I$ ). Once colonies became larger than $10-12$ cells, a pattern was established where ICAM-1+ cells tended to form a select subset of cells at the core of the colony and occasionally stretched to the outer edge of the colony (Fig. 6J). At $14 \mathrm{DIV}$, a $48 \mathrm{hr}$ incubation with BrDU indicated that a subpopulation $(<8 \%)$ of ICAM- $1+$ cells became BrDU + in vitro, but most ICAM-1+ cells (>90\%) did not become BrDU+ during the assay. In addition, the majority $(>95 \%)$ of BrDU + cells did not express ICAM-1 but were frequently clustered immediately adjacent to the ICAM-1+ population (Fig. $6 J$ ). Although these BrDU+ cells may represent a more committed (GBC) progenitor, the specific GBC antibodies available to us will not work in the conditions necessary for detecting BrDU in vitro.

After 14 DIV, HBCs plated on collagen presented distinct colony morphologies that also represented three major size classes (Fig. $6 K-M)$. Small colonies $(<30$ cells/colony) contained dispersed populations of process-bearing cells and demonstrated minimal proliferation. Medium colonies (30-150 cells/colony) formed tighter clusters of polygonal epithelioid cells surrounded with a penumbra of flatter cells in minimal media (Fig. 5B), with cells more dispersed in DMF/10, and large colonies (151-40,000 cells; average colony size, 5363 cells) contained small, densely 
packed, tightly adherent cells. Average population doubling time from 7 to 14 DIV on collagen was $109 \mathrm{hr}$ for small colonies, $68.4 \mathrm{hr}$ for medium colonies, and 28 $\mathrm{hr}$ for large colonies. After 14 DIV on a collagen matrix, ICAM-1+ cells could be detected in $95-100 \%$ of large colonies, $60-$ $65 \%$ of the medium colonies, and very few $(0-5 \%)$ of the small colonies (data not shown). Assayed at 14 DIV, the large colonies were highly heterogeneous for ICAM-1 expression, containing 5-65\% ICAM-1 + cells/total cells in colony.

Improving cloning efficiency of ICAM$1+\mathrm{HBCs}$ by reproducing components of the olfactory microenvironment The HBC expression profile of $\beta$ and $\alpha$ integrins (Fig. 2) demonstrated that in vivo, HBCs express potential receptors for collagen, laminin, or fibronectin. Collagen IV and laminin are also the primary components of the olfactory basal lamina (Julliard and Hartmann, 1998). We thus tested whether in a standard medium of DMF/ 10 , a mixed matrix that may better simulate the endogenous olfactory basal lamina, could promote the ability of ICAM-1selected cells to adhere, self-replicate, and produce colonies. In results paralleling those of the adhesion kinetics experiment (Fig. 6B), laminin and fibronectin alone were less effective at promoting $\mathrm{HBC}$ adhesion than collagen alone, and 54.9 and $42.5 \%$ as effective at producing colonies (Fig. 7A). On collagen, the different classes of colony size were equally represented (Fig. 7B). On fibronectin and laminin alone, however, $>75 \%$ of colonies at 14 DIV were dispersed, small colonies $(<30$ cells) (Fig. $7 B$ ). When collagen was mixed with laminin (either in 1:2 or 2:1 ratio), however, total cloning efficiency was increased 140-160\% over collagen alone (Fig. 7A). The increase in cloning efficiency on a mixed collagen:laminin substrate reflects a specific and significant increase in the representation of large colonies, where large colony formation was increased fourfold on a mixed laminin:collagen matrix compared with collagen (Fig. 7B).

Using Opti4 on collagen as the baseline (control) media, we then tested mitogens for their ability to improve cloning efficiency and expansion of ICAM-1+ cells. Initial experiments indicated that EGF, a mitogen known to enhance progenitor proliferation in the $\mathrm{OE}$ in vivo and in vitro, would stimulate colony formation in Opti4, with no observable change for EGF in DMF/ 10\% (Mahanthappa and Schwarting, 1993; Farbman and Buchholz, 1996; Getchell et al., 2000). Both EGF and TGF $\alpha$ in Opti4 were the single mitogens with the most significant improvement in cloning efficiency (224.9 and $188.7 \%$ over Opti4 alone, respectively), whereas EGF combined with TGF $\alpha$ was the most effective

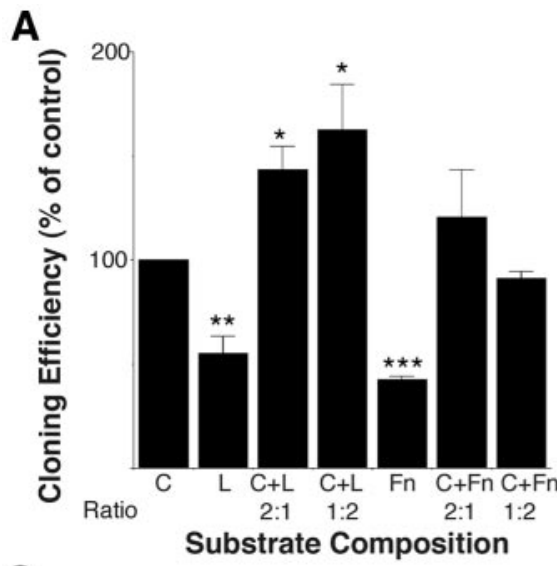

B
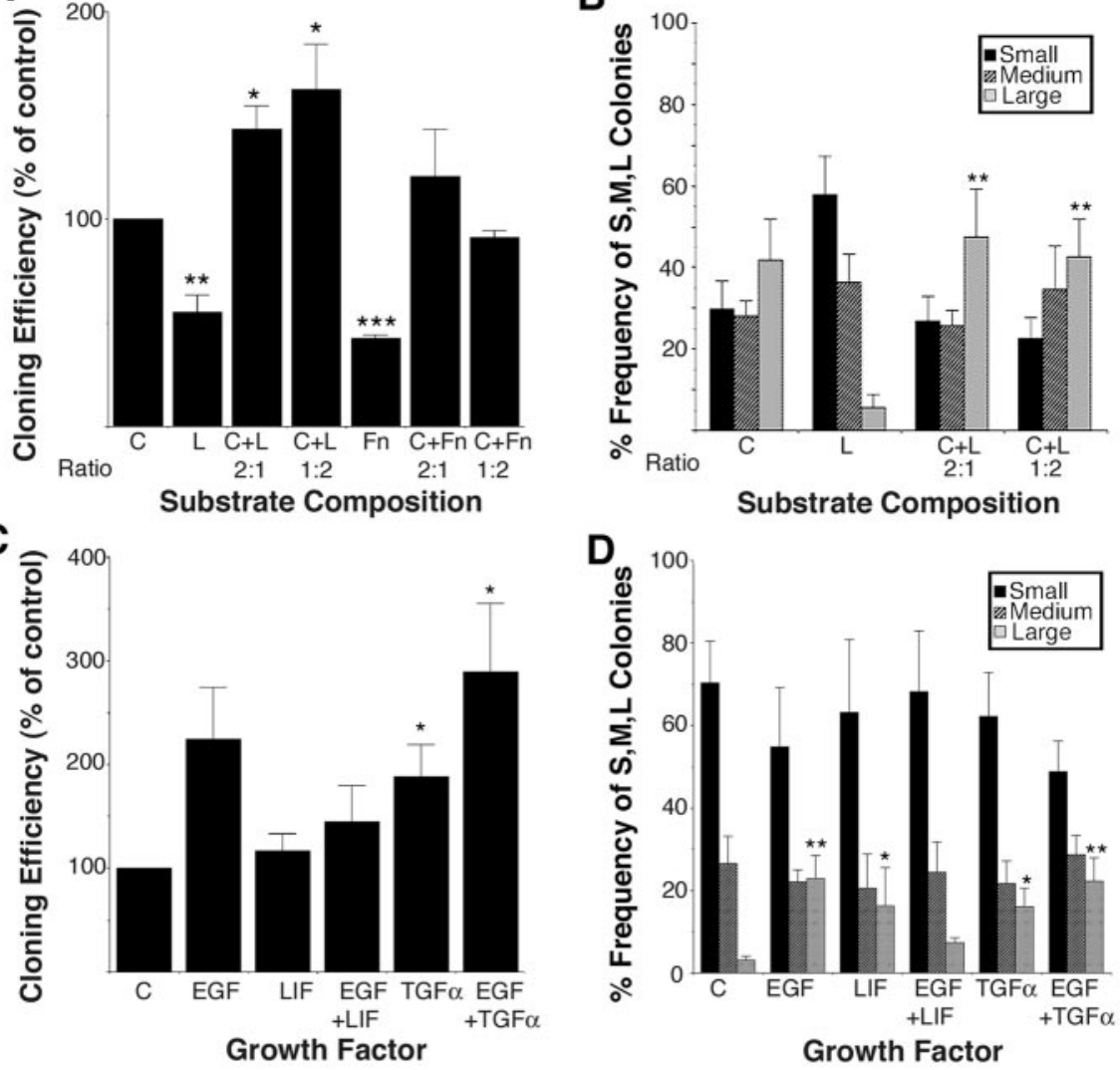

Growth Factor
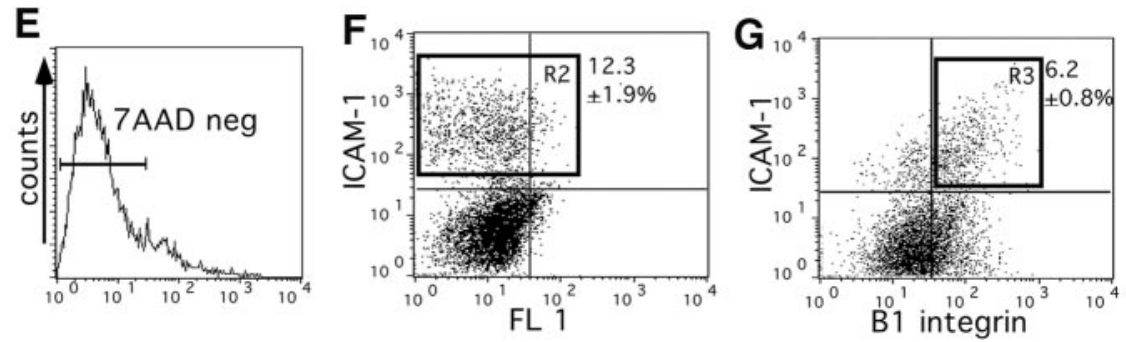

Figure 7. Optimizing cloning efficiency of ICAM-1-selected cells by substrate and growth factor selection. A, At clonal density, single ICAM-1 + cells adhered to a collagen (C) matrix, but overall cloning efficiency was significantly enhanced when collagen was mixed with laminin $(L)$ in a 1:2 ratio. Overall cloning efficiency was diminished when fibronectin (Fn) was included as a substrate $(n=4)$. $B$, The relative percentage of large colonies increased on a collagen:laminin mixed substrate, whereas a laminin-rich environment promoted the growth of small colonies at the expense of large colonies $(n=4)$. C, Overall cloning efficiency of ICAM-1 + HBCs on collagen, tested in 0pti-MEM/4\% FCS, was significantly enhanced in the presence of EGF (10 $\mathrm{ng} / \mathrm{ml})$ and further enhanced when a mixture of EGF and TGF $\alpha(0.5 \mathrm{ng} / \mathrm{ml})$ was used. $D$, Predominantly small colonies were generated from all ICAM-1 + cells grown in 0pti-MEM with 4\%FCS alone. However, the addition of EGF, LIF, and TGF $\alpha$ significantly increased the percentage of large colonies obtained primarily at the expense of small colonies. Statistical significance was calculated using a Student's $t$ test $(n=4-6) .{ }^{*} p<0.05 ;{ }^{* *} p<0.01 ;{ }^{* * *} p<0.0005$. E, For FACS, live cells were first gated by 7-AAD exclusion. $F, G$, They were then gated for ICAM-1 positivity $(F)(\mathrm{R} 2 ; 12.3 \pm 1.9 \%$ of live cells) or ICAM-1/ $\beta 1$ double positivity (R3; $6.2 \pm 0.8 \%$ of live cells) before plating $(G)$. mitogen mixture overall (289.3\% better than Opti4 alone) (Fig. 7C). In Opti4, neither $\beta$ FGF (data not shown) nor LIF significantly enhanced the initial number of colonies obtained. The increase in cloning efficiency with EGF and TGF $\alpha$ once again reflected a specific increase in the representation of large colonies, with little change in the incidence of small or medium colonies (Fig. 7C,D). When compared with Opti4 alone, the representation of large colonies increased 10-fold with EGF, fourfold with LIF, and fivefold with TGF $\alpha$ (Fig. 7D). In addition, large ICAM$1+$-seeded colonies plated in Opti4 with LIF $(10 \mathrm{ng} / \mathrm{ml})$ without additional media changes were capable of surviving, slowly ex- 
panding, and maintaining their in vitro phenotype for 4-6 months, whereas small and medium colonies did not survive beyond 4 weeks under these conditions (data not shown).

Having identified conditions that would improve the survival and cloning efficiency of MACS-isolated ICAM-1+ cells, we then performed FACS isolation of ICAM-1 + cells and doubly positive ICAM- $1+/ \beta_{1}$ integrin + cells. Using gating conditions for live cells, which highly expressed each of these antigens (Fig. $6 F, G$ ), we obtained $9814 \pm 2179$ ICAM- $1+$ cells per mouse OE $(12.27 \pm$ $1.9 \%)$ and $4654 \pm 396$ ICAM- $1+/ \beta_{1}$ integrin + cells per mouse OE $(6.24 \pm 0.86 \%)$ from the fraction already shown to contain the highest number of colony-forming cells. This yield was not significantly different when whole, unfractionated OE was used as source material, and is in line with the total estimated percentage of ICAM-1 + cells per total number of cells in OE $(6.59 \pm$ $1.24 \%$ ) in vivo. Although we obtained $45-50 \%$ fewer ICAM-1+ live $(7 \mathrm{AAD}+)$ (Fig. 6E) cells with FACS as opposed to MACS, this selection approach is more rigorous ( $>95 \%$ pure), and the overall cloning efficiency for ICAM- $1+(0.28 \pm 0.17 \%)$ in baseline control conditions (DMF/10 on collagen) was comparable with that obtained with MACS selection. Similarly, when FACSsorted cells were plated on collagen/laminin instead of collagen alone, cloning efficiency was increased 1.59-fold, with large colonies enriched at the expense of small colonies. All colonies were tested for secondary cloning, but, regardless of initial growth condition, neither small nor medium colonies appeared capable of forming adherent secondary colonies after passaging under these conditions. However, 30-35\% of large colonies expanded on laminin/collagen were capable of forming adherent secondary and tertiary colonies, with similarly low frequency $(0.2-0.4 \%$ cloning efficiency) to primary selected cells, in DMF10. The ratio of new colonies obtained ( small $>$ medium $>$ large) was similar to that seen in primary colony formation. When HBCs were selected on the basis of ICAM- $1+/ \beta_{1}$ integrin + double selection, cloning efficiency was only $57 \%$ of that of ICAM-1+ cells on collagen but was significantly enhanced when the cells were seeded onto a laminin/collagen mixed matrix or grown in DMF/ 10. The most significant difference in double-selected cells was the prevalence of small colonies, particularly when laminin was included in the matrix. Small colonies comprised $70-75 \%$ of all colonies seeded by ICAM- $1+/ \beta 1$ integrin + cells.

ICAM-1 + HBC-seeded colonies produce multiple differentiated progeny that are neuronal, glial, and olfactory specific

The small colonies from either ICAM- $1+$ or ICAM- $1+/ \beta-1+$ selection demonstrated limited capacity to proliferate, and their differentiated progeny were subsequently assayed as being predominantly glial (S100 $\beta$ or GFAP positive), with no evidence for neuronal progeny. In contrast, large colonies contained the highest percentage of ICAM- $1+/ \beta_{4}$ integrin-positive cells, displayed the maximal responses to EGF, TGF $\alpha$, and LIF (in vivo ligands that regulate OE neurogenesis), and were therefore hypothesized to contain the highest representation of neuroglial progenitors (potential stem cells). We therefore examined the potential for large colonies to generate a variety of differentiated progeny found within the olfactory system. ICAM-1+ cells were plated as single cells in either DMF/10 or Opti4 with EGF and LIF on a collagen/laminin substrate. After assessment of cloning efficiency at $14 \mathrm{DIV}$, all colonies were switched to fresh DMF/10 and allowed to differentiate for an additional 2-6 weeks. The resulting colonies (from 1-2 months in vitro) contained a core of adhesive cells with a variety of progeny that migrated either away from or
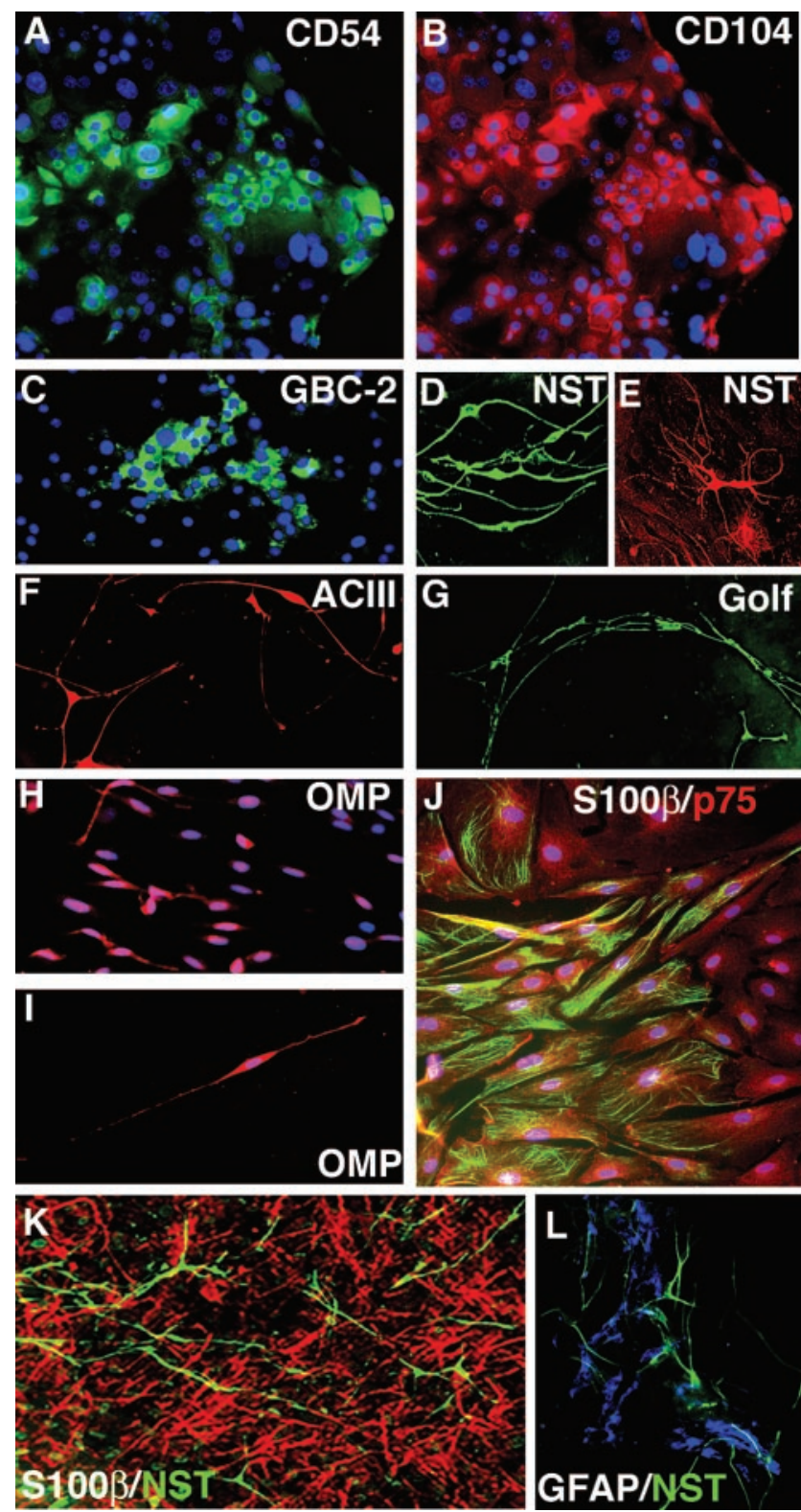

Figure 8. A single ICAM-1-selected horizontal basal cell can produce multiple differentiated neuronal and glial progeny. After the expansion of single ICAM-1+ cell into a colony on a laminin-collagen mixed substrate, ICAM-1 (CD54; $A$, green; DAPI nuclear stain) continues to be expressed in subpopulations of cells at the core of the adherent colony that also express $(B) \beta_{4}$ integrin (CD104; red). Small islands of cells positive for the GBC-2 (green) were also found within some large colonies. Cells migrating up from the colony were found to express $\beta$-III NST (D) $(\mathrm{TuJ} 1+)$ and have a bipolar morphology (green) and a multipolar morphology $(E$, red). Long bipolar cells, which formed streams of migrating cells leaving colonies and extending processes across the matrix, demonstrated robust process and cell body expression of the ACIII $\left(F\right.$, red) and the $G_{\text {olf }}(G$, green). $H$, The OMP (red) is expressed in the cell bodies (overlapping with DAPI to become purple) and some processes of cells with a bipolar morphology, which were found growing with other OMP-negative cells. I, Highest OMP expression levels were found in cells that had migrated into a substrate-rich, cell-poor region of the culture. Populations of cells resembling olfactory ensheathing cells ( $\$ 100 \beta$, green; $\mathrm{p} 75$ red) were frequently found in clusters but infrequently alone. Large colonies also generated intermingling populations of spindly S100 $\beta+$ glial cells ( $K$, red), NST + neurons (green), and flattened GFAP + glial cells ( $L$, blue) lying beneath networks of NST + (green) neurons.

on top of the colony and that exhibited a wide range of cellular morphologies and phenotypes (Fig. 8).

Within the colony core, a large percentage of the cells segregated into subpopulations that coexpressed ICAM- 1 and $\beta_{4}$ in- 
tegrin (CD54+/CD104+) (Fig. 8A,B). A significant degree of heterogeneity was also created within the colony core, however, where some regions were strongly ICAM-1/ $\beta 4$-positive and other larger, flattened cells were negative for either or both proteins (Fig. $8 A, B$ ). Cells expressing the globose basal cell marker, GBC-2, could occasionally be found grouped together (Fig. 8C) (Goldstein and Schwob, 1996). Type III $\beta$-NST (TuJ1) expression was detected in cells that exhibited a variety of neuronal morphologies (Roskams et al., 1998). These included bipolar cells resembling developing ORNs (Fig. 8D) and highly multipolar cells (most often found on a bed of sheet-like colony-derived cells), which do not resemble immature or mature ORNs (Fig. $8 E$ ). From 28-56 DIV, some small networks of bipolar, fasciculating cells that migrated away from the edge of the colony were found to express type III adenylate cyclase (ACIII) (Fig. $8 F$ ) and the olfactory G-protein $\left(\mathrm{G}_{\text {olf }}\right)$ (Fig. $8 G$ ) throughout their cell bodies and processes. A small percentage of cells $(<2 \%$ of cells with a bipolar neuronal morphology) also expressed the OMP (Farbman and Margolis, 1980) and exhibited a characteristic bipolar morphology of ORNs either when networking together (Fig. $8 \mathrm{H}$ ) or after migrating from the colony as individual cells (Fig. 8I). Large flattened migratory groups of cells, which appeared in the majority of differentiated cultures, coexpressed the olfactory ensheathing cell markers S100 $\beta$ and p75 (Fig. 8J) or p75 with glial fibrillary acidic protein (data not shown) (for review, see Ramon-Cueto and Avila, 1998). Mixed populations of neuronal (NST) and glial (either S100 $\beta$ or GFAP+) cells were also found interdigitating, where the neuronal cells were almost always arranged along the beds of glial cells (Fig. $8 K, L$ ).

\section{Discussion}

In this study, we identified a subpopulation of HBCs in vivo with an adhesion receptor expression profile similar to non-neural stem cells that can be clonally selected in defined in vitro conditions mimicking the olfactory microenvironment and generate multiple glial, neuronal, and progenitor phenotypes found in the mouse olfactory mucosa.

After olfactory bulb removal and widespread mature ORN apoptosis, a highly zonal pattern of neurogenesis is initiated in adjacent basal regions of OE (Fig. 1) (Carr and Farbman, 1992; Huard et al., 1998; Schwob, 2002). This is likely because of highly localized changes in induction or repression signaling from apoptotic ORNs (Cowan et al., 2001; Bauer et al., 2003), combined with differential shifts in lateral inhibition from adjacent cells, collectively removing inhibitory signals that permit only a subset of basal cells to respond to a mitotic stimulus (Shou et al., 2000; Morrison, 2001; Watt, 2001). Surprisingly, the contralateral OE also demonstrates a delayed but significant increase in basal cell mitosis, suggestive of a contralateral feedback neurogenesis in response to the loss of ipsilateral ORN input into the CNS (Fig. 1). At the peak of neurogenesis, most mitotic cells were presumptive GBCs, not HBCs (Fig. 1), consistent with a demonstrated GBC contribution to ORN genesis (Caggiano et al., 1994; Huard and Schwob, 1995). However, the most pluripotent progenitors of non-neural systems (true stem cells) are tightly regulated to preserve genomic integrity and divide rarely, opening the possibility that rarely dividing HBCs could still contain candidate potential OE stem cells.

However, HBCs lack expression of standard neural progenitor markers (Calof et al., 1998) and, although located in a neuroepithelium, bear a closer antigenic resemblance to non-nervous system epithelial stem cells of the epidermis, prostate, and colon (Potten and Booth, 2002; Watt, 2002). HBCs express ICAM-1, which regulates the mitosis of hematopoietic stem-progenitor cells in the bone marrow microenvironment (Arkin et al., 1991), and $\beta_{1}$ and $\beta_{4}$ integrins, which are restricted to the basal surface of many (but not all) HBCs, where complexes with $\alpha_{1}, \alpha_{3}$, or $\alpha_{6}$ integrin could form receptors for collagen, fibronectin, and laminin in the basal lamina (Fig. 2). ICAM-1 is coexpressed with cytokeratin in HBCs, but its overlap with either $\beta_{1}$ or $\beta_{4}$ integrin is more heterogeneous (Fig. 2), in accord with alternating patches of OE that demonstrate high and low integrin expression (Fig. 3). Because basal cell mitosis is compartmentalized in similar spatially arranged zones (Fig. 1), differential $\beta$-integrin expression could delineate distinct territories of potential stem cells or progenitor subpopulations within the HBC population, directly paralleling integrin-mediated regulation of progenitor proliferation and differentiation in the epidermis (Adams and Watt, 1991; Fuchs et al., 1997) and also the regulation of cerebellar progenitor differentiation by a $\beta$-integrin-laminin-mediated signaling (Blaess et al., 2004). In the OE, the heterogeneity of $\beta_{1}$ and $\beta_{4}$ integrin distribution in HBCs may thus designate molecular boundaries of more active versus quiescent $\mathrm{HBC}$ zones of neurogenesis (Graziadei and Graziadei, 1979a; Aiba et al., 1993; Getchell et al., 2000). Several of the HBC-based integrin signaling components reported here have also been highlighted as potentially the most highly conserved pathways in stem cell biology (Ramalho-Santos et al., 2002)

Apoptotic mature ORNs direct progenitor proliferation using a directed program different from that induced when ORNs die a nonapoptotic death, after detergent or MeBr ablation (Figs. 1, 3) (Roskams et al., 1998; Schwob, 2002; Jang et al., 2003). At the peak of apoptosis-induced mitosis, HBCs adjacent to dividing HBCs and GBCs increase adhesion receptor expression, presumably enhancing their retention on the basal lamina, whereas their more mobile neighbors participate in epithelial remodeling and neurogenesis (Fig. 3). Does the basal lamina of the OE thus change locally to inhibit or facilitate mitosis, or do extracellular signals first downregulate adhesion receptor expression in $\mathrm{HBCs}$ and then shift them into a more promitotic state? In the epidermis, a number of mechanisms [including localized secretion of matrix metalloproteases (MMPs)] locally alter the ECM niche, thus reducing integrin expression in progenitors (Watt, 2002). Similarly, in the OE, local ensheathing cells (which secrete basal lamina ECM), are ideally situated to detect the loss of mature ORN axons and remodel basal lamina via MMPs or ECM secretion in a highly localized manner (summarized in Fig. 9) (Au and Roskams, 2003; Tsukatani et al., 2003).

Consistent with combinatorial adhesion receptor expression suggestive of a progenitor-like capacity, HBCs expressing ICAM- 1 with $\beta_{1}$ or $\beta_{4}$ integrin generated $>95 \%$ of the OE adherent colony-forming units at clonal density (Figs. 5-7), similar to heterogeneous colonies derived from $\beta_{1}$ integrin-expressing putative stem cells of the epidermis (Jones and Watt, 1993). Immediately after adhesion in vitro, single cells coexpressed ICAM-1 with either $\beta_{1}$ or $\beta_{4}$ integrin and expanded symmetrically and asymmetrically to form increasingly heterogeneous colonies containing expanded populations of morphologically similar BrDU-positive and negative ICAM-1 + HBCs and also mitotic ICAM-negative progeny (Fig. 6). The heterogeneity of ICAM-1+ HBC-seeded colonies is similar to epidermal keratinocytes, where a continuum of colony-forming progenitors of varying proliferative and differentiative capacities produce smaller colonies initiated by transit amplifying cells and larger colonies seeded by cells with a more stem-like potential (Barrandon and Green, 1987). 


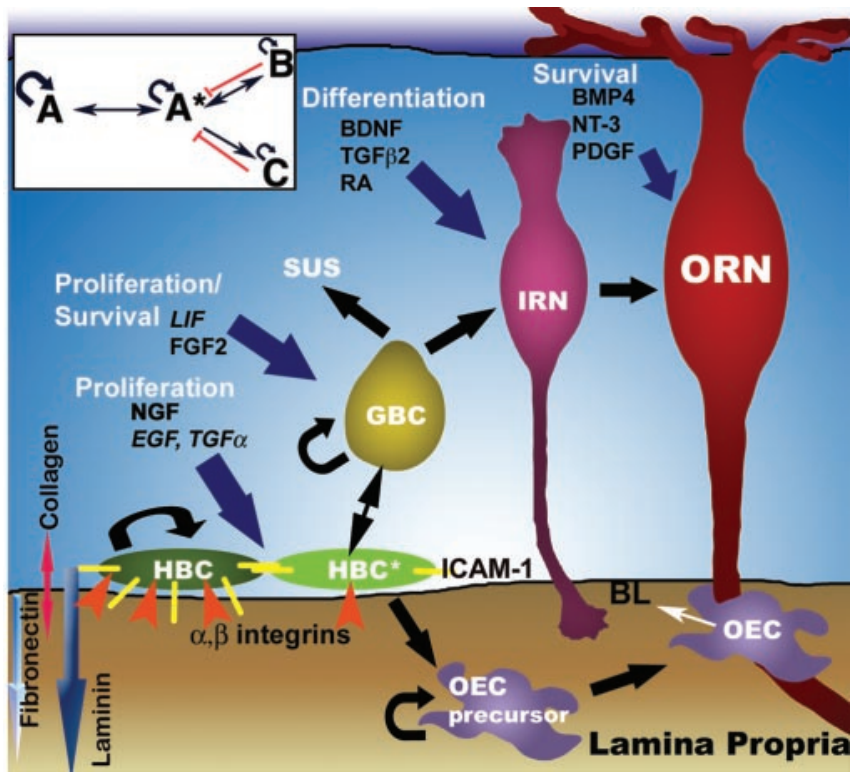

Figure 9. Factors that regulate the interaction of progenitor subtypes in the olfactory epithelium. HBCs can self renew (size of curved arrow indicates capacity to divide-self-renew) and exist in a tightly adherent and loosely adherent $\left(\mathrm{HBC}^{*}\right)$ mitotic phenotypes, which are differentiated by their expression levels of ICAM-1 (yellow) and $\alpha$ and $\beta$ integrin complexes (orange arrows). A more restricted neuronal-sustentacular (SUS) progenitor is found in the GBC population, whereas a gliogenic precursor can also be derived from mitotic $\mathrm{HBC}$. ECM gradients for laminin, collagen, and fibronectin are indicated, along with the factors that combine with matrix stimulation to positively regulate the balance between progenitor subtypes and immature and mature cells within the $\mathrm{OE}$ and lamina propria. Inset simplifies the relationship between different $0 \mathrm{E}$ progenitor subtypes, where $B(\mathrm{GBC})$ and $C(\mathrm{OEC}-\mathrm{GRPs})$ reside in entirely different $E C M$, cell- cell, and growth factor environments within the $O E$ and lamina propria.

After selection, the overall cloning efficiency of ICAM-1+ HBCs was maximal on a mixed collagen-laminin matrix most closely mimicking OE basal lamina (Julliard and Hartmann, 1998) (Fig. 7) that would also maximally stimulate the integrin combinations expressed on subsets of HBCs in vivo (Fig. 2). Laminin alone enhanced formation of small colonies that demonstrated a limited proliferative capacity and morphological characteristics similar to glial-restricted precursors (GRPs) (Rao et al., 1998) and primarily glial progeny. ICAM- $1+/ \beta_{1}$ integrinpositive FACS-isolated cells (Fig. 7) yielded almost exclusively small colonies, suggesting that a laminin- $\beta_{1}$ integrin pathway appears to bias toward an HBC-derived glial-committed progenitor phenotype. Medium colonies also produced glial progeny, but some colonies were neuronal, producing small populations of immature NST-expressing cells closely resembling the shortlived neuronal progenitor colonies derived from NCAMnegative embryonic OE (Mumm et al., 1996).

Large colony production (cloning efficiency and expansion) was specifically enhanced on mixed collagen-laminin and contained the highest percentage of ICAM-1+ cells after 14 DIV.

Expanded populations of HBCs coexpressing ICAM-1 with $\beta_{4}$ integrin (Figs. 2, 3; Table 1) were found primarily in large colonies, the only colonies that could generate secondary and tertiary colonies (Fig. 8). Again, primarily large colonies contained grouped populations of GBC-2-positive GBCs, which, although presumably generated from an ICAM-1-expressing founder cell, could themselves then contribute to the production of more committed progeny within the colony (Chen et al., 2004; Iwema et al., 2004; McMillan Carr et al., 2004). We surmise that large colonies were likely seeded by HBC-derived ICAM-1+ cells ex- pressing the highest levels of combinations of mixed $\alpha$ and $\beta$ integrins (where $\beta_{4}$ complexes increase response to mixed matrix), which in turn represent the more multipotent progenitors.

EGF and TGF $\alpha$ together most significantly enhanced the cloning efficiency and production of larger colonies from ICAM-1+ HBCs, presumably via the HBC-expressed EGF receptor (Krishna et al., 1996). Given that multiple progenitor phenotypes exist in the OE, EGF signaling may regulate a switch between more committed and less committed progenitors, as it does elsewhere in the nervous system (Doetsch et al., 2002). LIF did not significantly enhance cloning efficiency but did increase both survival and size of large colonies obtained. Because apoptotic (and not necrotic) ORNs upregulate both LIF (Getchell et al., 2002; Bauer et al., 2003) and nerve growth factor (Roskams et al., 1996), LIF could positively direct proliferation and survival via LIF receptors (on GBC subpopulations), which could laterally inhibit $\mathrm{HBC}$ division and differentiation and promote the retention of a more stable stem-like HBC population (Oka et al., 2002). The differential lifespan, size, and passage-ability of the colonies here closely parallels that seen in ependymal and subependymal clones (Chiasson et al., 1999), whereas smaller, shortterm, dispersed colonies displayed heterogeneous phenotypes consistent with the short-term committed progenitors generated from an NCAM-negative fraction of embryonic OE (Mumm et al., 1996), colony-forming restricted progenitors from the developing retina (Cayouette et al., 2003), and glial-restricted precursors from the developing neural tube (Rao et al., 1998).

Fourteen days after initial colony formation, FBS stimulated the spontaneous generation of more highly heterogeneous differentiated cells (both glial and neuronal) from individual large colonies (Fig. 8). The olfactory ACIII, $\mathrm{G}_{\text {olf }}$, and the OMP arose in rare $(<2 \%)$ bipolar cells that usually migrated away from colonies, demonstrating that a small number of ORN-like cells were spontaneously generated. Each large colony examined demonstrated subpopulations of cells coexpressing the glial markers S100 $\beta$ with either $\mathrm{p} 75$ or GFAP in an expression pattern reminiscent of OECs and developing Schwann cells (for review, see Ramon-Cueto and Avila, 1998). In addition to classic bipolar IRN-like cells, some multipolar cells expressing NST were generated that did not resemble any cells yet reported in ORN cultures (Calof and Chikaraishi, 1989; Mahanthappa and Schwarting, 1993; Farbman and Buchholz, 1996; Roskams et al., 1996). The presence of nonolfactory neuronal and glial lineages derived from defined progenitors obtained from the OE basal cell layer in vitro has not been previously reported, although alternative neuronal and glial lineages are generated from olfactory progenitors in embryonic development (Wray et al., 1989). This suggests that ICAM- $1+/ \beta_{1}$-negative HBCs that seed large colonies have a greater degree of pluripotency than other previously reported progenitors from the OE (Mumm et al., 1996; Chen et al., 2004) that may be controlled in part by the ECM environment of their location, at the interface between neuronal and glial environments (Fig. 9). A model has thus emerged in which the OE contains multiple progenitor subtypes (Fig. $9 A-D$, inset), where large colonies are comprised of $\mathrm{A}$ (HBCs), $\mathrm{A}^{*}$ (mitotic HBCs), B (GBCs), and $\mathrm{C}$ (OEC-GRPs), medium colonies are initiated by $\mathrm{A}^{*}$ and also contain either $\mathrm{B}$ or $\mathrm{C}$, and small colonies are seeded by $\mathrm{A}^{\star}$ cells, which transition immediately to $\mathrm{B}$ or $\mathrm{C}$.

In conclusion, we examined the dynamics of quiescent and activated $\mathrm{OE}$ progenitor populations in vivo and identified a characteristic adhesion receptor signature of putative multipotent progenitors in HBCs of the OE. Our findings suggest that convergent integrin and primitive growth factor pathways regu- 
late OE-derived progenitors in vivo and in vitro (Fig. 9). The HBC integrin profile lead us to develop selective in vitro ECM and growth factor microenvironments that can promote retention of an HBC phenotype in vitro. HBCs now emerge as a heterogeneous population containing candidate progenitors that can generate olfactory (and nonolfactory) neural lineages as well as glial cells and GBCs from single cells. These data suggest parallels to related CNS-derived progenitor populations (Chiasson et al., 1999), where two adjacent OE basal cell populations contain two main subpopulations of progenitors, one of which is more committed to generate OE-based cells (ORNs, sustentacular cells) and the other (the HBC-derived population examined here) is neuroglial. These accessible OE-derived HBC progenitors may not only hold potential for the development of autologous therapeutic approaches in animal models but also for probing the interface of ECM and growth factor signaling in neuroglial progenitor regulation.

\section{References}

Adams JC, Watt FM (1990) Changes in keratinocyte adhesion during terminal differentiation: reduction in fibronectin binding precedes alpha 5 beta 1 integrin loss from the cell surface. Cell 63:425-435.

Adams JC, Watt FM (1991) Expression of beta 1, beta 3, beta 4, and beta 5 integrins by human epidermal keratinocytes and non-differentiating keratinocytes. J Cell Biol 115:829-841.

Aiba T, Mori J, Nakai Y (1993) Nerve growth factor (NGF) and its receptor in rat olfactory epithelium. Acta Otolaryngol Suppl (Stockh) 506:37-40.

Arkin S, Naprstek B, Guarini L, Ferrone S, Lipton JM (1991) Expression of intercellular adhesion molecule-1 (CD54) on hematopoietic progenitors. Blood 77:948-953.

Au E, Roskams AJ (2003) Olfactory ensheathing cells of the lamina propria in vivo and in vitro. Glia 41:224-236.

Barrandon Y, Green H (1987) Three clonal types of keratinocyte with different capacities for multiplication. Proc Natl Acad Sci USA 84:2302-2306.

Bauer S, Rasika S, Han J, Mauduit C, Raccurt M, Morel G, Jourdan F, Benahmed M, Moyse E, Patterson PH (2003) Leukemia inhibitory factor is a key signal for injury-induced neurogenesis in the adult mouse olfactory epithelium. J Neurosci 23:1792-1803.

Blaess S, Graus-Porta D, Belvindrah R, Radakovits R, Pons S, LittlewoodEvans A, Senften M, Guo H, Li Y, Miner JH, Reichardt LF, Muller U (2004) Beta1-integrins are critical for cerebellar granule cell precursor proliferation. J Neurosci 24:3402-3412.

Booth C, Potten CS (2000) Gut instincts: thoughts on intestinal epithelial stem cells. J Clin Invest 105:1493-1499.

Caggiano M, Kauer JS, Hunter DD (1994) Globose basal cells are neuronal progenitors in the olfactory epithelium: a lineage analysis using a replication-incompetent retrovirus. Neuron 13:339-352.

Calof AL, Chikaraishi DM (1989) Analysis of neurogenesis in a mammalian neuroepithelium: proliferation and differentiation of an olfactory neuron precursor in vitro. Neuron 3:115-127.

Calof AL, Mumm JS, Rim PC, Shou J (1998) The neuronal stem cell of the olfactory epithelium. J Neurobiol 36:190-205.

Carr VM, Farbman AI (1992) Ablation of the olfactory bulb up-regulates the rate of neurogenesis and induces precocious cell death in olfactory epithelium. Exp Neurol 115:55-59.

Cayouette M, Barres BA, Raff M (2003) Importance of intrinsic mechanisms in cell fate decisions in the developing rat retina. Neuron 40:897-904

Chen X, Fang H, Schwob JE (2004) Multipotency of purified, transplanted globose basal cells in olfactory epithelium. J Comp Neurol 469:457-474.

Chiasson BJ, Tropepe V, Morshead CM, van der Kooy D (1999) Adult mammalian forebrain ependymal and subependymal cells demonstrate proliferative potential, but only subependymal cells have neural stem cell characteristics. J Neurosci 19:4462-4471.

Costanzo RM, Graziadei PP (1983) A quantitative analysis of changes in the olfactory epithelium following bulbectomy in hamster. J Comp Neurol 215:370-381.

Cowan CM, Thai J, Krajewski S, Reed JC, Nicholson DW, Kaufmann SH, Roskams AJ (2001) Caspases 3 and 9 send a pro-apoptotic signal from synapse to cell body in olfactory receptor neurons. J Neurosci 21:7099-7109.

DeHamer MK, Guevara JL, Hannon K, Olwin BB, Calof AL (1994) Genesis of olfactory receptor neurons in vitro: regulation of progenitor cell divisions by fibroblast growth factors. Neuron 13:1083-1097.

Doetsch F, Petreanu L, Caille I, Garcia-Verdugo JM, Alvarez-Buylla A (2002) EGF converts transit-amplifying neurogenic precursors in the adult brain into multipotent stem cells. Neuron 36:1021-1034.

Farbman AI (1990) Olfactory neurogenesis: genetic or environmental controls? Trends Neurosci 13:362-365.

Farbman AI, Buchholz JA (1996) Transforming growth factor-alpha and other growth factors stimulate cell division in olfactory epithelium in vitro. J Neurobiol 30:267-280.

Farbman AI, Margolis FL (1980) Olfactory marker protein during ontogeny: immunohistochemical localization. Dev Biol 74:205-215.

Frisch SM, Francis H (1994) Disruption of epithelial cell-matrix interactions induces apoptosis. J Cell Biol 124:619-626.

Fuchs E, Dowling J, Segre J, Lo SH, Yu QC (1997) Integrators of epidermal growth and differentiation: distinct functions for beta 1 and beta 4 integrins. Curr Opin Genet Dev 7:672-682.

Gage FH (2000) Mammalian neural stem cells. Science 287:1433-1439.

Getchell TV, Narla RK, Little S, Hyde JF, Getchell ML (2000) Horizontal basal cell proliferation in the olfactory epithelium of transforming growth factor-alpha transgenic mice. Cell Tissue Res 299:185-192.

Getchell TV, Shah DS, Partin JV, Subhedar NK, Getchell ML (2002) Leukemia inhibitory factor mRNA expression is upregulated in macrophages and olfactory receptor neurons after target ablation. J Neurosci Res 67:246-254.

Goldstein BJ, Schwob JE (1996) Analysis of the globose basal cell compartment in rat olfactory epithelium using GBC-1, a new monoclonal antibody against globose basal cells. J Neurosci 16:4005-4016.

Graziadei GA, Graziadei PP (1979a) Neurogenesis and neuron regeneration in the olfactory system of mammals. II. Degeneration and reconstitution of the olfactory sensory neurons after axotomy. J Neurocytol 8:197-213.

Graziadei PP, Graziadei GA (1979b) Neurogenesis and neuron regeneration in the olfactory system of mammals. I. Morphological aspects of differentiation and structural organization of the olfactory sensory neurons. J Neurocytol 8:1-18.

Huard JM, Schwob JE (1995) Cell cycle of globose basal cells in rat olfactory epithelium. Dev Dyn 203:17-26.

Huard JM, Youngentob SL, Goldstein BJ, Luskin MB, Schwob JE (1998) Adult olfactory epithelium contains multipotent progenitors that give rise to neurons and non-neural cells. J Comp Neurol 400:469-486.

Hynes RO (1992) Integrins: versatility, modulation, and signaling in cell adhesion. Cell 69:11-25.

Iwema CL, Fang H, Kurtz DB, Youngentob SL, Schwob JE (2004) Odorant receptor expression patterns are restored in lesion-recovered rat olfactory epithelium. J Neurosci 24:356-369.

Jang W, Youngentob SL, Schwob JE (2003) Globose basal cells are required for reconstitution of olfactory epithelium after methyl bromide lesion. J Comp Neurol 460:123-140.

Jones PH, Watt FM (1993) Separation of human epidermal stem cells from transit amplifying cells on the basis of differences in integrin function and expression. Cell 73:713-724.

Julliard AK, Hartmann DJ (1998) Spatiotemporal patterns of expression of extracellular matrix molecules in the developing and adult rat olfactory system. Neuroscience 84:1135-1150.

Krishna NS, Little SS, Getchell TV (1996) Epidermal growth factor receptor mRNA and protein are expressed in progenitor cells of the olfactory epithelium. J Comp Neurol 373:297-307.

Luskin MB (1993) Restricted proliferation and migration of postnatally generated neurons derived from the forebrain subventricular zone. Neuron 11:173-189.

Mahanthappa NK, Schwarting GA (1993) Peptide growth factor control of olfactory neurogenesis and neuron survival in vitro: roles of EGF and TGF-beta s. Neuron 10:293-305.

McKay R (2000) Stem cells and the cellular organization of the brain. J Neurosci Res 59:298-300.

McMillan Carr V, Ring G, Youngentob SL, Schwob JE, Farbman AI (2004) Altered epithelial density and expansion of bulbar projections of a discrete HSP70 immunoreactive subpopulation of rat olfactory receptor neurons 
in reconstituting olfactory epithelium following exposure to methyl bromide. J Comp Neurol 469:475-493.

Morrison SJ (2001) Neuronal potential and lineage determination by neural stem cells. Curr Opin Cell Biol 13:666-672.

Mumm JS, Shou J, Calof AL (1996) Colony-forming progenitors from mouse olfactory epithelium: evidence for feedback regulation of neuron production. Proc Natl Acad Sci USA 93:11167-11172.

Oka M, Tagoku K, Russell TL, Nakano Y, Hamazaki T, Meyer EM, Yokota T, Terada N (2002) CD9 is associated with leukemia inhibitory factormediated maintenance of embryonic stem cells. Mol Biol Cell 13:1274-1281.

Potten CS, Booth C (2002) Keratinocyte stem cells: a commentary. J Invest Dermatol 119:888-899.

Potten CS, Loeffler M (1990) Stem cells: attributes, cycles, spirals, pitfalls and uncertainties. Lessons for and from the crypt. Development 110:1001-1020.

Ramalho-Santos M, Yoon S, Matsuzaki Y, Mulligan RC, Melton DA (2002) "Stemness": transcriptional profiling of embryonic and adult stem cells. Science 298:597-600.

Ramon-Cueto A, Avila J (1998) Olfactory ensheathing glia: properties and function. Brain Res Bull 46:175-187.

Rao MS, Noble M, Mayer-Proschel M (1998) A tripotential glial precursor cell is present in the developing spinal cord. Proc Natl Acad Sci USA 95:3996-4001.

Roskams AJ, Bethel MA, Hurt KJ, Ronnett GV (1996) Sequential expression of Trks A, B, and C in the regenerating olfactory neuroepithelium. J Neurosci 16:1294-1307.

Roskams AJ, Cai X, Ronnett GV (1998) Expression of neuron-specific betaIII tubulin during olfactory neurogenesis in the embryonic and adult rat. Neuroscience 83:191-200.

Sastry SK, Horwitz AF (1996) Adhesion-growth factor interactions during differentiation: an integrated biological response. Dev Biol 180:455-467.

Schwob JE (2002) Neural regeneration and the peripheral olfactory system. Anat Rec 269:33-49.
Schwob JE, Szumowski KE, Stasky AA (1992) Olfactory sensory neurons are trophically dependent on the olfactory bulb for their prolonged survival. J Neurosci 12:3896-3919.

Schwob JE, Youngentob SL, Meiri KF (1994) On the formation of neuromata in the primary olfactory projection. J Comp Neurol 340:361-380.

Shou J, Rim PC, Calof AL (1999) BMPs inhibit neurogenesis by a mechanism involving degradation of a transcription factor. Nat Neurosci 2:339-345.

Shou J, Murray RC, Rim PC, Calof AL (2000) Opposing effects of bone morphogenetic proteins on neuron production and survival in the olfactory receptor neuron lineage. Development 127:5403-5413.

Suzuki Y, Takeda M (1993) Basal cells in the mouse olfactory epithelium during development: immunohistochemical and electron-microscopic studies. Brain Res Dev Brain Res 73:107-113.

Tsukatani T, Fillmore HL, Hamilton HR, Holbrook EH, Costanzo RM (2003) Matrix metalloproteinase expression in the olfactory epithelium. NeuroReport 14:1135-1140.

van der Kooy D, Weiss S (2000) Why stem cells? Science 287:1439-1441.

Watt FM (2001) Stem cell fate and patterning in mammalian epidermis. Curr Opin Genet Dev 11:410-417.

Watt FM (2002) Role of integrins in regulating epidermal adhesion, growth and differentiation. EMBO J 21:3919-3926.

Weiler E, Farbman AI (1997) Proliferation in the rat olfactory epithelium: age-dependent changes. J Neurosci 17:3610-3622.

Weiss S, van der Kooy D (1998) CNS stem cells: where's the biology (a.k.a. beef)? J Neurobiol 36:307-314.

Wray S, Grant P, Gainer H (1989) Evidence that cells expressing luteinizing hormone-releasing hormone mRNA in the mouse are derived from progenitor cells in the olfactory placode. Proc Natl Acad Sci USA 86:8132-8136.

Zhu AJ, Haase I, Watt FM (1999) Signaling via betal integrins and mitogenactivated protein kinase determines human epidermal stem cell fate in vitro. Proc Natl Acad Sci USA 96:6728-6733. 